\title{
Genetic Improvement for Yield and Its Components through Induced Chemical and Physical Mutagenesis in Peanut (Arachis Hypogaea L.)
}

\author{
Salah A. Okasha; Shawky E. Ammar; Abdelrahem A. Aly and Seham H. Salama \\ Agronomy Department, Faculty of Agriculture, Suez Canal University, 41522 Ismailia, Egypt
}

Received: $14 / 2 / 2021$

\begin{abstract}
The present study was conducted at private Farm at El-Sharqia Governorate, Egypt under supervision of Agronomy Department, Faculty of Agriculture, Suez Canal University, Ismailia, Egypt. Four cultivars of peanut were used in this work namely NC9, Gregory, Bold, and Runner. This work aimed to study the induction of genetic variation in peanut using Sodium azide $\left(\mathrm{NaN}_{3}\right.$; Mw $\left.=65.01\right)$ with two doses $\left(1 \times 10^{-3}\right)$ and $\left(3 \times 10^{-3}\right)$ and three doses of Gamma rays $(10,30$ and $50 \mathrm{kr})$ to induce mutagenesis. M1 and M2 seeds per dose for each genotype including the control were sown in a randomized complete block design (RCBD) with three replications in 2017 and 2018 summer seasons. Analysis of variance showed that there were significant differences between genotypes under sodium azide and gamma rays for most studied traits in M1 and M2 generations. Number of primary branches was significantly affected by sodium azide concentrations, however all genotypes gave low number of primary branches under $0.003 \mathrm{M}$ than other treatments in both generations. Gregory and NC9 cultivars under Gamma rays had the high number of branches/plant in M1 and M2 generation when treated with $0.001 \mathrm{M}$ compared with $0.003 \mathrm{M}$. The average of plant height was affected by radiation mutagen and higher the effect of sodium azide mutagen in both generations. 100-seed weight was affected significantly by sodium azide mutagen more than those by radiation mutagen in both generations. Maximum values of seed yield/plant were recorded for the NC9 followed by Gregory in both generations. NC9 and Gregory had the maximum values of seed yield/plant, when they treated by $0.001 \mathrm{~m}$ in both generations. Mean values of oil content were increased significantly with increasing concentration of gamma rays doses in M1 and M2 at $10 \mathrm{kr}, 30 \mathrm{kr}$ and $50 \mathrm{kr}$, respectively compared with control. The Bold cultivar had the highest values $51.34 \%$ and $50.39 \%$ and runner cultivar with values 49.02 and 49.66, when they treated with $50 \mathrm{kr}$ and $30 \mathrm{kr}$ in M1 generation. The Runner and NC9 gave the high values for yield and its components and oil content of most genetic parameters under different mutagens in M1 and M2 generations for the most studied traits. The results of heritability, showed moderate to high values for most characters under studied in different mutagens in M1 and M2 generations. Pod yield/plant under the effect of sodium azide appears high positive correlation coefficients with each of seed yield/plant (0.869 and 0.928$)$ during two the generations and 100 -seed weight (0.643) in M1 generation.
\end{abstract}

Keywords: Mutations, peanut, Phenotypic and genotypic correlations, variance, seed yield and its component

\section{INTRODUCTION}

Peanut (Arachis hypogaea L.) is a selfpollinated crop, an allote traploid $(2 \mathrm{n}=4 \mathrm{x}=40)$, belonging to the family Fabaceae, sub-family Papilionidae, genus Arachis and species hypogaea (Isleib et al., 1994). Peanut is an annual herb of indeterminate growth habit. It ranks thirteenth among the world food crops, fourth as most important source of edible oil and third as most important source of vegetable protein (FAOSTAT, 2020). Globally, the largest use of peanut is for oil by ratio (43-55\%), with the meal being used as a high protein dietary supplement for human and animal consumption. Peanut cultivated in more than 100 countries on 26.4 million hectares worldwide with total production of 36.5 million tones resulting in an average productivity of 1.4 t/ha, of which China (41\%), India (21\%), Nigeria (8\%) and United States of America (7\%) are the largest producers (FAOSTAT, 2020). Though the peanut crop has morphological, biochemical, physiological variability, it has narrow genetic base, because of its monophyletic origin, lack of gene flow due to ploidy barrier and self- pollination. The most popular method employed for creating genetic variability, is induced mutagenesis through chemical and physical irradiation. Plant breeders have almost exhausted the natural genetic variability amenable to genetic improvement of the crop. Breeding for improved crop varieties depends on the availability of genetic variation and effective selection methods. Hybridization followed by selection in segregating generations has been used to generate variability in peanut varieties. Emasculation and pollination procedures of hybridization are cumbersome and the success rate of making crosses is generally low (Janila et al., 2013).

Gamma rays are electromagnetic radiations with the shorter wavelength (shorter than X-rays). It is one of the important physical agents used to improve the characters and productivity of many plants (Jaywardena and Peiris, 1988). Irradiation also been successfully used for mutation breeding of various crops and ornamental plants and has proven an adept means of encouraging the expression of recessive genes and producing new genetic variations (Schum, 2003). Mutation breeding has contributed significantly to plant improvement. According to Lagoda (2009), 2,700 mutant varieties were officially released from 170 different plant species in more than 60 countries and recorded in the FAO/IAEA Mutant Varieties Database (MVD).

Chemical mutagenesis is a simple approach to create mutation in plants for their improvement of potential agronomic traits. Chemical mutagens like ethyl-nitroso-urea; methyl-nitroso-urea, ethyl-methane sulphonate (EMS) and sodium azide (SA) are also used for mutation assisted breeding. Among all chemical mutagenesis, sodium azide $\left(\mathrm{NaN}_{3}\right)$ is considered as safe and has capability of producing high frequency of 
mutation. Sodium azide is well known of heavy metal enzymes with influences on metabolism and respiration of living cell. It creates point mutation and damages the chromosomes and thus produces tolerance in the plants for numerous adverse conditions, the effect of the SA is greatly depends on the $\mathrm{pH}$ of the treatment solution (Abdul Rahaman et al., 2013; Jadhav et al., 2018). The successful utilization of sodium azide to generate genetic variability in plant breeding has been reported in peanut (Mensah and Obadoni, 2007), barley and mungbean (Roychowdhury et al., 2012). The main objectives of this work were i) to study the effect of some chemical and physical mutagen substances on the morphological and physiological particularities of the peanut genotypes ii) to induce genetic variability using gamma rays and sodium azide mutagens as well as study genotypic and phenotypic correlations among some economic traits in four peanut cultivars, taken differential in sensitivity of cultivars into account.

\section{MATERIALS AND METHODS}

\section{Plant material and mutants treatment:}

Four peanut cultivars 'NC9, Gregory, Runner and Bold have been used in this study were obtained from Agriculture Research Center, Giza, Egypt.

\section{Mutagens treatments}

Chemical mutagen; Sodium azide (NaN3; $\mathrm{Mw}=65.01)$ was used with two doses $(1 \times 10-3)$ and (3×10-3).

Sodium azide $(\mathrm{NaN} 3 ; \mathrm{Mw}=65.01)$. Two Sodium azide solutions were used, prepared at $\mathrm{pH}=3.5$ using phosphate buffer. The concentrations of $\mathrm{NaN}_{3}$ used in this investigation were $1.0 \times 10^{-3}$ and $3.0 \times 10^{-3}$ molar. The seed samples were submerged in the solution for 2 hours. After treatment the treated seed were washed in running tap water for one hour.

Physical mutagens; Gamma rays were used with three doses $(10,30$ and $50 \mathrm{kr})$ to induce mutagenesis.

Gamma rays. From $C^{0} 60$ source at the Middle Eastern Regional Radioisotopes Center for Arab countries, Dokki, Giza. Three doses were used 10, 30 and $50 \mathrm{kr}$ at dose rate of $2 \backslash .59 \mathrm{r} / \mathrm{sec}$ in the first season. The treated and untreated seeds were sown to arise $\mathrm{M}_{1}$ generation in May 15, 2017. The M2 seeds were raised by selfin $\backslash g$ M1 plants for each genotype, the seeds collected from the different plants of each treatment were bulked to give rise to $\mathrm{M}_{2}$ generation. In the second season, the bulked seeds of each M1 treatment and untreated were sown in May, 15, 2018 in the field with a spacing of $0.75 \mathrm{~m}$ between rows and $0.40 \mathrm{~m}$ between plants in a row. Plot size was a single $4 \mathrm{~m}$ row. Two seeds were planted per hill and seedlings were thinned to one plant per stand. Two weeks after emergence to achieve 15 plants per row. In the first and second seasons, all the cultural practices were performed as recommended.

Germination percentage (GP), days to flowering (DF), number of primary branches/plant (NB), plant height $(\mathrm{PH})$, number of pods/plant (NP), pod yield/plant (PP), 100-seed weight(SW), seed yield/plant(SYP), shelling percentage (SHP), seed oil content percentage (SO) and chlorophyll SPAD values were recorded in M1 and M2.

Statistical analysis, all data were subjected to statistical analysis according to Steel et al. (1997) two ways ANOVA to compare the effects of chemical and physical mutagen on peanut cultivars with randomized complete block design with three replicates. The genotypic and phenotypic variances ( $\mathrm{Vg}$ and $\mathrm{Vp}$ ), broad sense heritability (h) and genotypic and phenotypic coefficient of variability (G.C.V. \% and P.C.V.\%) computed according to Singh and Choudhary (1985). Expected genetic advance (in M2 generation) was calculated according to Allard (1964). The genotypic and phenotypic correlation coefficients were estimated according to Miller et al. (1958).

\section{RESULTS AND DISCUSSION}

Results of analysis of variance of the studied agronomic traits in M1 and M2 generations are summarized in Tables (1-11). Sodium azide and Gamma doses significantly affected the variations of all traits in both generations. Four peanut cultivars differed significantly for all traits; the significance among cultivars indicated a wide range of variability between cultivars. The cultivar $\times$ doses interaction was also highly significant for all the traits at both generations. Therefore, these cultivars were differentially affected by the mutagens in terms of induction of genetic variations.

\section{I- Mean performance of peanut varieties}

The results obtained from analysis of variance showed that there were significant differences between genotypes (NC9, Gregory, Bold and Runner) under sodium azide $(0.001$ and 0.003$)$ and gamma rays $(10$, 30 and 50kr) for most the studied characters in M1 and M2 generations. The significance among genotypes indicated a wide range of variability between peanut cultivars as shown in Tables (1-11). Various treatments of the mutagens (i.e. sodium azide and gamma rays) and mutagens $\times$ genotypes interaction showed significant differences for all studied characters in M1 and M2 generations, indicating that the genotypes differently responded for the different mutagens. These results are in agreement with Gunasekaran and Pavadai (2015) and Jadhav et al. (2018).

\section{Growth yield and yield components}

\section{A. Growth characters}

Vegetative growth of the four peanut cultivars as affected by used different a sodium azide and gamma rays was determined. The results of characters, which were taken into consideration, are presented as follows:-

\section{Germination percentage}

Means of germination percentage under field conditions for the studied cultivars under investigation treated with sodium azide and gamma rays in both generations are given in Table (1).

The statistical analysis was concluded that, varietal differences and doses effect in addition to their interaction were significant in both generations. Germination $\%$ was gradually decreased with 
increasing dose application during the two generations. For sodium azide, the dose $0.003 \mathrm{M}$ had the lowest significant values $(78.89 \%$ and $79.45 \%)$ in $\mathrm{Ml}$ and $\mathrm{M} 2$ generations, respectively. However, the control treatment gave the highest values $(88.89 \%$ and 89.45$)$ in $\mathrm{M} 1$ and M2 generations, respectively. The means also indicated that the NC9 cultivar had the higher values of germination percentage followed by Bold cultivar compared with the other cultivars in M1 and M2 generations. The interaction between cultivars and doses revealed that the observed values of NC9 and Gregory treated with $0.001 \mathrm{M}$ were the highest ones in both generations. Regarding to the effect of Gamma ray, the analysis of variance indicated that differences in germination percentage due to concentration effect were significant in M1 and M2 generations. Results obtained showed that all gamma rays treatments significantly decreased germination $\%$ in both generations. The treatment $50 \mathrm{Kr}$ had the lowest significant values $(77.78 \%$ and $84.44 \%)$ in $\mathrm{M} 1$ and M2 generations, in respectively. The varietal were significant differences in M1 and M2 generations. The cultivar NC9 and Bold had the highest values than others in M1 generation for this trait, while in M2 generation, the NC9 and Runner cultivar had the highest values and the lowest values of germination percentage were obtained from Gregory in both generations. Comparing the two mutagen sodium azide and gamma rays concerning this trait, the germination was more reduced in sodium azide compared to gamma rays in both generations. These results are in agreement with Siddiqui et al. (2007), Aparna et al. (2012), Padmaja et al. (2015), Jadhav et al. (2018).

Table (1): Effect of Sodium azide and Gamma rays on germination \% in field for peanut varieties at M1 and M2 generations

\begin{tabular}{|c|c|c|c|c|c|c|c|c|c|c|c|}
\hline & & \multicolumn{5}{|c|}{ M1 } & \multicolumn{5}{|c|}{ M2 } \\
\hline & & NC9 & Gregory & Bold & Runner & $\mathbf{X}$ & NC9 & Gregory & Bold & Runner & $\mathbf{X}^{\prime}$ \\
\hline \multirow{3}{*}{$\begin{array}{l}\text { Sodium } \\
\text { azide } \\
\text { (M) }\end{array}$} & Con. & 91.11 & 86.67 & 91.11 & 86.67 & 88.89 & 91.11 & 86.67 & 88.89 & 91.11 & 89.45 \\
\hline & 0.001 & 86.67 & 86.67 & 84.44 & 80.00 & 84.45 & 86.67 & 84.44 & 82.22 & 80.00 & 83.33 \\
\hline & 0.003 & 82.22 & 75.56 & 82.22 & 75.56 & 78.89 & 86.67 & 75.56 & 77.78 & 77.78 & 79.45 \\
\hline \multicolumn{2}{|l|}{$\mathbf{X}^{`}$} & 86.67 & 82.97 & 85.92 & 80.74 & & 88.15 & 82.22 & 82.96 & 82.96 & \\
\hline \multirow{4}{*}{$\begin{array}{l}\text { Gamma } \\
\text { rays } \\
(\mathbf{K r})\end{array}$} & Con. & 91.11 & 86.67 & 91.11 & 86.67 & 88.89 & 91.11 & 86.67 & 88.89 & 91.11 & 89.45 \\
\hline & $10 \mathrm{kr}$ & 91.11 & 80.00 & 91.11 & 86.67 & 87.22 & 91.11 & 84.44 & 86.67 & 88.89 & 87.78 \\
\hline & $30 \mathrm{kr}$ & 88.89 & 80.00 & 84.44 & 86.67 & 85.00 & 88.89 & 82.22 & 84.44 & 86.67 & 85.56 \\
\hline & $50 \mathrm{kr}$ & 75.56 & 80.00 & 82.22 & 73.33 & 77.78 & 88.89 & 82.22 & 84.44 & 82.22 & 84.44 \\
\hline \multicolumn{2}{|l|}{$\mathbf{X}^{\top}$} & 86.67 & 81.67 & 87.22 & 83.34 & & 90.00 & 83.89 & 86.11 & 87.22 & \\
\hline \multirow{4}{*}{\multicolumn{2}{|c|}{ L.S.D 5\% }} & $\bar{V}$ & $\bar{S}$ & & $V \times S$ & & $\bar{V}$ & $\bar{S}$ & & $V \times S$ & \\
\hline & & $4.81^{*}$ & $5.90 *$ & & $8.34^{*}$ & & $5.95^{*}$ & $6.28 *$ & & $7.56^{*}$ & \\
\hline & & $\mathbf{V}$ & $\mathbf{G}$ & & $\mathbf{V} \times \mathbf{G}$ & & V & $\mathbf{G}$ & & $\mathbf{V} \times \mathbf{G}$ & \\
\hline & & $5.87 *$ & $6.82 *$ & & $8.64 *$ & & $4.76^{*}$ & $4.12 *$ & & $7.24 *$ & \\
\hline
\end{tabular}

\section{Days to flowering}

The character of days to flowering plays a significant role in altering the life cycle duration of any plant. The mutagen succeeded in inducing variability in days to flowering of plants in all studied cultivars of peanut. It can be seen from the Table (2) that there was an increase in the mean days to flowering in all cultivars with increase in concentration of sodium azide and doses of gamma.

The significant changes in terms of days to flower were observed in 0.003 concentration of sodium azide than the control and the rest of treatments. Days to first flower, ranged from 34.92 to 39.0 days in M1 and from 40.0to 41.25 days in M2 respectively. A minimum decrease in days to first flower was recorded in runner genotypes 29.33 and 28.33 days in M1 and M2 generations, respectively.

With regard to interaction between cultivars and sodium azide in M1 generation, Runner and NC9 had the lowest no. of days to flowering, Runner, and Gregory in M2 generation, when treated with $0.001 \mathrm{M}$ and $0.003 \mathrm{M}$ compared with control.
On the other hand, statistical analysis of days to flowering indicated that gamma rays affected variation differences and interaction of both factors under study in both generations.

The results in Table (3) showed that all gamma rays doses significantly increased days to first flower in both generations. The treatment $10 \mathrm{kr}$ had the lowest values $38.25 \%$ and 41.75 days in M1 and M2 generations, respectively. The cultivar NC9 and Runner had the lowest values than others in M1 and M2 generation for this trait. The results of interaction between cultivars and doses of gamma rays showed that the Runner cultivar had the lowest no. of days to flowering in M1 and M2 generations when treated with $10 \mathrm{kr}$ and $30 \mathrm{kr}$ compared with control. In general, the plants germinated from seeds, which were treated with sodium azide, or gamma rays took the longest duration for corresponding trait. These results are similar with found by Animasaun et al. (2014), Gunasekaran and Pavadai (2015), and Muniappan et al. (2016). 
Table (2): Effect of Sodium azide and Gamma rays on number of days to flowering in field for peanut varieties at M1 and M2 generations

\begin{tabular}{|c|c|c|c|c|c|c|c|c|c|c|c|}
\hline & & \multicolumn{5}{|c|}{ M1 } & \multicolumn{5}{|c|}{ M2 } \\
\hline & & NC9 & Gregory & Bold & Runner & $\mathbf{X}^{\prime}$ & NC9 & Gregory & Bold & Runner & $\mathbf{X}^{\vee}$ \\
\hline \multirow{3}{*}{$\begin{array}{l}\text { Sodium } \\
\text { azide } \\
\text { (M) }\end{array}$} & Con. & 31.67 & 40.00 & 40.00 & 28.00 & 34.92 & 41.00 & 46.00 & 45.00 & 28.00 & 40.00 \\
\hline & 0.001 & 35.00 & 42.00 & 43.00 & 30.00 & 37.50 & 46.00 & 43.00 & 46.00 & 28.00 & 40.75 \\
\hline & 0.003 & 40.00 & 43.00 & 43.00 & 30.00 & 39.00 & 46.00 & 44.00 & 46.00 & 29.00 & 41.25 \\
\hline \multirow[t]{2}{*}{$X^{\prime}$} & & 35.56 & 41.67 & 42.00 & 29.33 & & 44.33 & 44.33 & 45.67 & 28.33 & \\
\hline & Con. & 31.67 & 40.00 & 40.00 & 28.00 & 34.92 & 40.00 & 45.00 & 43.00 & 25.00 & 38.25 \\
\hline \multirow{3}{*}{$\begin{array}{l}\text { Gamma } \\
\text { rays } \\
(\mathbf{K r})\end{array}$} & $10 \mathrm{kr}$ & 32.00 & 45.00 & 44.00 & 32.00 & 38.25 & 37.00 & 50.00 & 48.00 & 32.00 & 41.75 \\
\hline & $30 \mathrm{kr}$ & 35.00 & 43.00 & 45.00 & 32.00 & 38.75 & 39.00 & 52.00 & 48.00 & 32.00 & 42.75 \\
\hline & $50 \mathrm{kr}$ & 37.00 & 45.00 & 45.00 & 33.00 & 40.00 & 40.00 & 46.00 & 49.00 & 34.00 & 42.25 \\
\hline \multicolumn{2}{|l|}{$X^{\prime}$} & 33.92 & 43.25 & 43.50 & 31.25 & & 39.00 & 48.25 & 47.00 & 30.75 & 33.92 \\
\hline \multirow{4}{*}{\multicolumn{2}{|c|}{ L.S.D $5 \%$}} & $\overline{\mathrm{V}}$ & $\bar{S}$ & & $\mathrm{~V} \times \mathrm{S}$ & & $\bar{V}$ & $\bar{S}$ & & $\mathrm{~V} \times \mathrm{S}$ & \\
\hline & & $4.54 *$ & $3.9^{*}$ & & $7.87 * *$ & & $4.31 *$ & $2.53 *$ & & $6.06^{*}$ & \\
\hline & & V & $\mathrm{G}$ & & $\mathrm{V} \times \mathrm{G}$ & & V & G & & $\mathrm{V} \times \mathrm{G}$ & \\
\hline & & $3.71 *$ & $2 . .85^{*}$ & & $5.34^{*}$ & & $3.92 *$ & $3.41 *$ & & $5.33 *$ & \\
\hline
\end{tabular}

\section{Number of branches/plant}

Number of primary branches was significantly affected by sodium azide concentration (Table 3), however all genotypes gave low number of primary branches under $0.003 \mathrm{M}(11.08)$ and (11.37) than other treatments in M1 an M2 generations, respectively. The results illustrated in Table (3) showed that the Gregory and NC9 gave the highest number of primary branches /plant, wherever, they gave 13.85, 13.78 and 14.06, 13.79 branches/plant in M1 and M2, respectively. Concerning to interaction between cultivars and sodium azide, Gregory had the highest no. of branches/plant in M1 and M2 generations, when treated with $0.001 \mathrm{M}$ compared with $0.003 \mathrm{M}$. With regard to Gamma rays, the number of branches per plant varied from 10.19 to 13.28 in the treated cultivars as compared to control 13.38 in M1 and varied from 10.69 to 12.13 as compared to control 13.48 in M2 Table (3). The Gregory and NC9 gave the highest number of primary branches/plant in M1 and M2 with values $(14.28,13.17)$ and $(13.36,13.15)$, respectively. Concerning to interaction between cultivars and gamma rays doses Gregory and NC9 had the high no. of branches/plant in M1 and M2 generations when treated with $10 \mathrm{kr}$ compared with $50 \mathrm{kr}$. These results are agreement with found by Animasaun et al. (2014), Gunasekaran and Pavadai (2015), Kavera and Nadaf (2017) and Gemechis (2018).

Table (3): Effect of Sodium azide and Gamma rays on number of branches/plant for peanut cultivars at M1 and M2 generations

\begin{tabular}{|c|c|c|c|c|c|c|c|c|c|c|c|}
\hline & \multicolumn{5}{|c|}{ M1 } & \multicolumn{5}{|c|}{ M2 } \\
\hline & & NC9 & Gregory & Bold & Runner & $\mathbf{x}$ & NC9 & Gregory & Bold & Runner & $\mathbf{X}^{`}$ \\
\hline \multirow{3}{*}{$\begin{array}{l}\text { Sodium } \\
\text { azide } \\
\text { (M) }\end{array}$} & Con. & 14.53 & 15.17 & 13.40 & 10.40 & 13.38 & 14.97 & 14.97 & 13.20 & 10.77 & 13.48 \\
\hline & 0.001 & 13.97 & 14.07 & 12.43 & 7.87 & 12.09 & 13.10 & 15.33 & 11.87 & 8.97 & 12.32 \\
\hline & 0.003 & 12.83 & 12.30 & 11.87 & 7.30 & 11.08 & 13.30 & 11.87 & 11.77 & 8.53 & 11.37 \\
\hline $\mathbf{x}$ & & 13.78 & 13.85 & 12.57 & 8.52 & & 13.79 & 14.06 & 12.28 & 9.42 & \\
\hline \multirow{4}{*}{$\begin{array}{l}\text { Gamma } \\
\text { rays } \\
(\mathbf{K r})\end{array}$} & Con. & 14.53 & 15.17 & 13.40 & 10.40 & 13.38 & 14.97 & 14.97 & 13.20 & 10.77 & 13.48 \\
\hline & $10 \mathrm{kr}$ & 14.20 & 15.63 & 13.40 & 9.87 & 13.28 & 13.73 & 14.20 & 10.50 & 10.07 & 12.13 \\
\hline & $30 \mathrm{kr}$ & 13.40 & 15.33 & 12.07 & 8.40 & 12.30 & 12.73 & 13.07 & 12.30 & 8.30 & 11.60 \\
\hline & $50 \mathrm{kr}$ & 11.30 & 10.97 & 10.63 & 7.87 & 10.19 & 11.17 & 10.43 & 11.97 & 9.17 & 10.69 \\
\hline $\mathbf{X}$ & & 13.36 & 14.28 & 12.38 & 9.14 & & 13.15 & 13.17 & 11.99 & 9.58 & \\
\hline \multirow{4}{*}{ L.S.D 5\% } & & V & $\mathrm{S}$ & & $\mathrm{V} \times \mathrm{S}$ & & V & $\mathrm{S}$ & & $\mathrm{V} \times \mathrm{S}$ & \\
\hline & & $1.87^{*}$ & $1.62 *$ & & $3.25^{*}$ & & $0.81^{*}$ & $0.70^{*}$ & & $1.40^{*}$ & \\
\hline & & V & G & & $\mathrm{V} \times \mathrm{G}$ & & V & G & & $\mathrm{V} \times \mathrm{G}$ & \\
\hline & & $0.81^{*}$ & $0.71 *$ & & $1.41 *$ & & $0.92 *$ & $0.77^{*}$ & & $2.4^{*}$ & \\
\hline
\end{tabular}




\section{Plant height}

Means of plant height under field conditions for the studied cultivars under investigation treated with sodium azide and gamma rays in both generations are given in Table (4). Analysis of variance for all cultivars, mutantgens (Sodium azide and Gamma rays) and their interactions were showed significant differences for plant height in M1 and M2. With regard to sodium azide, plant height of all cultivars in the control conditions was the tallest $(87.57,88.52 \mathrm{~cm})$ than $0.001(82.34,80.29 \mathrm{~cm})$ and $0.003(66.32,79.44 \mathrm{~cm})$ in M1 and M2as shown in Table (4). Maximum plant height was recorded for the Bold cultivar (87.10 and 88.04) in M1 and M2, respectively followed by NC9 $(81.07 \mathrm{~cm})$ and $(84.81 \mathrm{~cm})$ while Runner and Gregory displayed the shortest plant height in M1 and M2. The effect of interaction between different cultivars and sodium azide treatments on plant height, means of M1 and M2 generations indicated that NC9 and Bold had the maximum height, when they treated by 0.001 , while Gregory and runner were the shortest than others when they treated with $0.003 \mathrm{M}$ in M1 and M2 generations. The results concerning the effect of radiation doses (gamma rays) revealed that, in M1 and M2 generations on plant height gradually decreased with increasing dose up to $50 \mathrm{Kr}$ Table (4). Maximum plant height was recorded for the Bold cultivar (89.31 and $89.80 \mathrm{~cm})$ in $\mathrm{M} 1$ and $\mathrm{M} 2$, respectively followed by Runner $(87.22$ and $89.80 \mathrm{~cm})$, while Gregory displayed the shortest plant height in both M1 and M2. The interactions between gamma rays and cultivars on plant height were shown in Table (4). Means of M1 and M2 generations indicated that Runner and Bold had the maximum height when they treated by $10 \mathrm{kr}$ and $30 \mathrm{kr}$, while Gregory and NC9 were the shortest than others when they treated with $30 \mathrm{kr}$ and $50 \mathrm{Kr}$ in both M1 and M2 generations. It can be also noticed that average of plant height of plants affected by radiation mutagen were higher than affected by sodium azide mutagen in M1 and M2 generations. These results suggested that radiation mutagen may be more valid for improvement height of peanut than sodium azide. These results are similar with found by Animasaun et al. (2014), Gunasekaran and Pavadai (2015), Kavera and Nadaf (2017) and Gemechis (2018).

Table (4): Effect of Sodium azide and Gamma rays on plant height $(\mathrm{cm})$ for peanut varieties at M1 and M2 generations

\begin{tabular}{|c|c|c|c|c|c|c|c|c|c|c|c|}
\hline & & \multicolumn{5}{|c|}{ M1 } & \multicolumn{5}{|c|}{ M2 } \\
\hline & & NC9 & Gregory & Bold & Runner & $\mathbf{X}^{\prime}$ & NC9 & Gregory & Bold & Runner & $\mathbf{X}$ \\
\hline \multirow{3}{*}{$\begin{array}{l}\text { Sodium } \\
\text { azide } \\
\text { (M) }\end{array}$} & Con. & 83.43 & 79.63 & 92.20 & 95.00 & 87.57 & 86.63 & 80.50 & 91.87 & 95.07 & 88.52 \\
\hline & 0.001 & 86.67 & 83.30 & 86.00 & 73.40 & 82.34 & 88.17 & 79.93 & 87.73 & 65.33 & 80.29 \\
\hline & 0.003 & 73.10 & 63.63 & 83.10 & 45.43 & 66.32 & 79.63 & 75.73 & 84.53 & 77.87 & 79.44 \\
\hline $\mathbf{X}^{\prime}$ & & 81.07 & 75.52 & 87.10 & 71.28 & & 84.81 & 78.72 & 88.04 & 79.42 & \\
\hline \multirow{4}{*}{$\begin{array}{c}\text { Gamma } \\
\text { rays } \\
\text { (Kr) }\end{array}$} & Con. & 83.43 & 79.63 & 92.20 & 95.00 & 87.57 & 86.63 & 80.50 & 91.87 & 95.07 & 88.52 \\
\hline & $10 \mathrm{kr}$ & 81.20 & 79.33 & 86.53 & 90.33 & 84.35 & 81.97 & 86.31 & 91.40 & 91.53 & 87.80 \\
\hline & $30 \mathrm{kr}$ & 75.40 & 78.30 & 89.97 & 86.33 & 82.50 & 78.87 & 78.73 & 86.30 & 88.87 & 83.19 \\
\hline & $50 \mathrm{kr}$ & 77.17 & 71.77 & 88.53 & 77.20 & 78.67 & 76.87 & 69.63 & 89.63 & 83.73 & 79.97 \\
\hline $\mathbf{X}^{\mathrm{x}}$ & & 79.30 & 77.26 & 89.31 & 87.22 & & 81.09 & 78.79 & 89.80 & 89.80 & \\
\hline \multirow{4}{*}{\multicolumn{2}{|c|}{ L.S.D 5\% }} & $\overline{\mathrm{V}}$ & $S$ & & $\mathrm{~V} \times \mathrm{S}$ & & $\mathrm{V}$ & $\mathrm{S}$ & & $\mathrm{V} \times \mathrm{S}$ & \\
\hline & & $5.72 *$ & $4.42 *$ & & $10.84 *$ & & $4.87^{*}$ & $3.63 *$ & & $6.25^{*}$ & \\
\hline & & $\mathrm{V}$ & $\mathrm{G}$ & & $\mathrm{V} \times \mathrm{G}$ & & V & G & & $\mathrm{V} \times \mathrm{G}$ & \\
\hline & & $4.12^{*}$ & $3.22 *$ & & $8.61^{*}$ & & $3.26^{*}$ & $4.71 *$ & & $7.03 *$ & \\
\hline
\end{tabular}

\section{B. Yield and yield components characters}

\section{Number of pods / plant:}

Results in Table (5) showed mean values for number of pods / plant in M1 and M2 generations. Analysis of variance for all cultivars, mutagens and their interactions showed significant differences for number of pods/ plant in both M1 and M2 generations. For sodium azide, number of pods/plant was decreased significantly with increasing sodium azide concentrations in M1 and M2 generations compared with control. Number of pods/plant of all cultivars in the control conditions was higher (73.5 and 81.4) than 0.001 (67.1 and 74.2) and 0.003 (57.6 and 66.9) in M1 and M2 as shown in Table (5). Maximum number of pods/plant was recorded for the Runner cultivar (99.1 and 107.7) in M1 and M2, respectively followed by Gregory (59.3 and 67.5), while NC9 and Bold displayed the lowest number of pods/plant in M1 and
M2, respectively as average of all sodium azide applications. Concerning to the effect of interaction between four cultivars and sodium azide applications for number of pods/plant, means of M1 and M2 generations indicated that Runner had the highest values, when it treated with 0.001 and $0.003 \mathrm{M}$, while Bold and NC9 were the lowest than the others when they treated with 0.001 and $0.003 \mathrm{M}$ in M1 and M2 generations. The results concerning to the effect of radiation doses (gamma rays) on number of pods/plant showed gradually decreased with increasing dose up to $50 \mathrm{Kr}$ compared with control from $73.5 \mathrm{kr}$ and 81.4 to 55.0 and 62.9 revealed that, in M1 and M2 generations Table (5). Maximum number of pods/plant was recorded for the runner cultivar (97.1 and 107.1) followed by Gregory (58.8 and 68.4) in M1 and M2, respectively, while NC9 displayed the lowest value in both M1 and M2 for this trait. The interaction between 
gamma rays application and cultivars on number of pods/plant was shown in Table (5), The Runner cultivar had the maximum values, when it treated by10, 30 and $50 \mathrm{kr}$, while NC9 and Bold were the lowest than others when they treated with $30 \mathrm{kr}$ and $50 \mathrm{Kr}$ in both M1 and M2 generations. These results are similar with found by Kavera and Nadaf (2017) and Gemechis (2018).

Table (5): Effect of Sodium azide and Gamma rays on number of pods / plant for peanut varieties at M1 and M2 generations

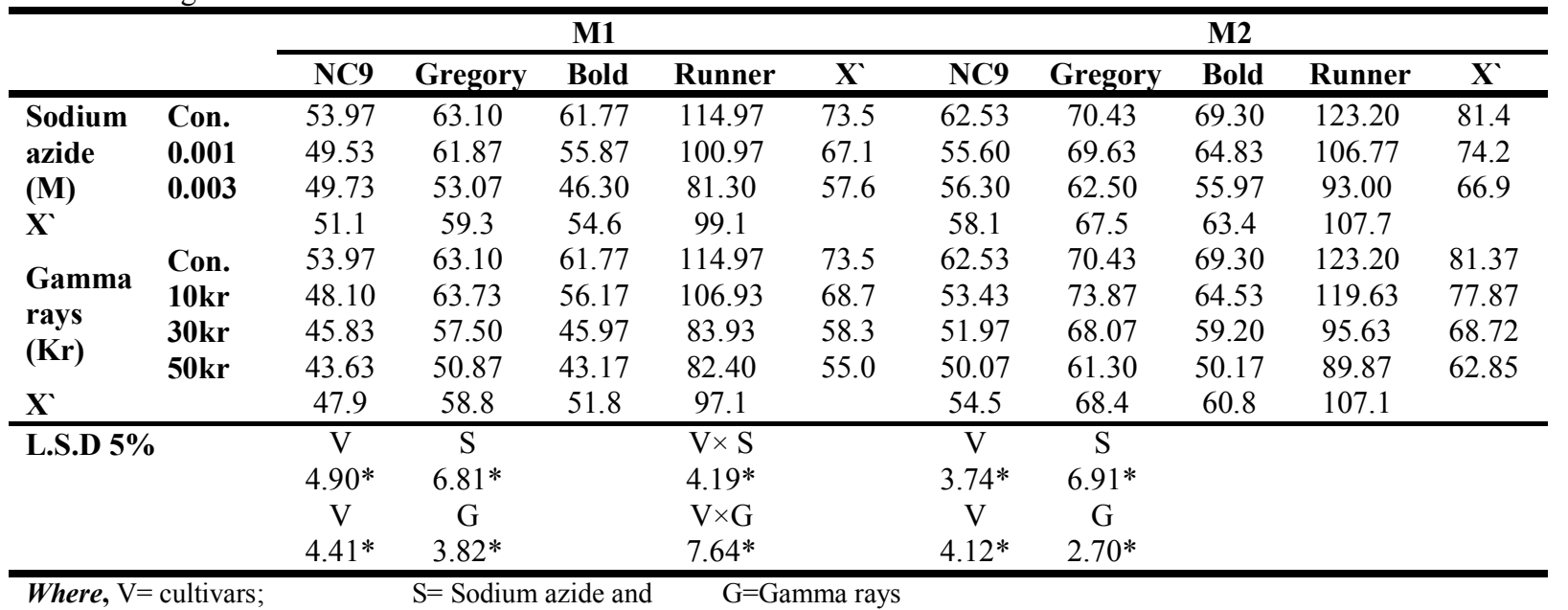

Where, $\mathrm{V}=$ cultivars

$=$ Sodium azide and

sodium azide (103.47 and $96.87 \mathrm{~g}$ ) in M1 and M2 as

\section{Pods weight/plant:}

The results in Table (6) showed mean values of pods weight /plant in M1 and M2 generations. Analysis of variance for all cultivars, mutagens and their interactions showed significant differences for mean values of pods / plant in both generations.

For sodium azide applications, mean values of pods weight / plant had the same trend as found in pods number /plant. Mean values of pods weight / plant were decreased significantly with increasing sodium azide concentration in both $\mathrm{M} 1$ and $\mathrm{M} 2$ generations compared with control. Pods weight / plant of all cultivars in the control conditions was higher (112.37 and 138.74) than $0.001(109.38$ and110.62g) and 0.003 shown in Table (6). Maximum number of pods weight/plant was recorded for the Gregory cultivar $(123.4$ and $138.0 \mathrm{~g})$ in $\mathrm{M} 1$ and $\mathrm{M} 2$, respectively followed by NC9 (121.2 and $122.9 \mathrm{~g}$ ), while Bold and Runner displayed the lowest values for this trait in M1 and M2 as average of all sodium azide applications. Concerning to the effect of interaction between four cultivars and sodium azide applications for pods weight/plant, the Gregory genotype had the highest values $(124.40 \mathrm{~g})$, when it treated with $0.001 \mathrm{M}$ in $\mathrm{M} 1$, while Bold and Runner gave the lowest pod weight/plant than other when they treated with 0.001 and $0.003 \mathrm{M}$ in $\mathrm{M} 1$ and $\mathrm{M} 2$ generations.

Table (6): Effect of Sodium azide and Gamma rays on Pods yield / plant (g) for peanut varieties at M1 and M2 generations

\begin{tabular}{|c|c|c|c|c|c|c|c|c|c|c|c|}
\hline & \multicolumn{5}{|c|}{ M1 } & \multicolumn{5}{|c|}{ M2 } \\
\hline & & NC9 & Gregory & Bold & Runner & $\mathbf{X}$ & NC9 & Gregory & Bold & Runner & $\mathbf{X}$ \\
\hline \multirow{3}{*}{$\begin{array}{l}\text { Sodium } \\
\text { azide } \\
(\mathrm{M})\end{array}$} & Con. & 123.83 & 127.73 & 101.3 & 96.63 & 112.37 & 154.20 & 139.5 & 88.87 & 172.4 & 138.74 \\
\hline & 0.001 & 118.87 & 124.40 & 107.63 & 86.63 & 109.38 & 131.93 & 134.4 & 82.97 & 93.2 & 110.62 \\
\hline & 0.003 & 121.07 & 117.97 & 98.77 & 76.07 & 103.47 & 82.57 & 140.17 & 65.97 & 98.77 & 96.87 \\
\hline $\mathbf{X}^{\prime}$ & & 121.25 & 123.36 & 102.56 & 86.44 & & 122.9 & 138.02 & 79.27 & 121.45 & \\
\hline \multirow{4}{*}{$\begin{array}{l}\text { Gamma } \\
\text { rays } \\
(\mathbf{K r})\end{array}$} & Con. & 123.83 & 127.73 & 101.3 & 96.63 & 112.37 & 154.2 & 139.5 & 88.87 & 172.4 & 138.74 \\
\hline & $10 \mathrm{kr}$ & 115.43 & 123.3 & 69.4 & 67.77 & 93.98 & 137.83 & 136.07 & 68.73 & 90.2 & 108.20 \\
\hline & $30 \mathrm{kr}$ & 128.1 & 124.4 & 57.87 & 71.07 & 95.36 & 94.17 & 136.63 & 85.53 & 113.1 & 107.35 \\
\hline & $50 \mathrm{kr}$ & 128.83 & 102.2 & 54.53 & 99.97 & 112.37 & 126.2 & 119.4 & 63.4 & 119.3 & 107.07 \\
\hline $\mathbf{X}^{\top}$ & & 124.05 & 119.41 & 70.78 & 83.86 & & 128.1 & 132.9 & 76.63 & 123.75 & \\
\hline \multirow{4}{*}{\multicolumn{2}{|c|}{ L.S.D 5\% }} & $\mathrm{V}$ & $\mathrm{S}$ & & $\mathrm{V} \times \mathrm{S}$ & & $\overline{\mathrm{V}}$ & $\mathrm{S}$ & & $\mathrm{V} \times \mathrm{S}$ & \\
\hline & & $9.60 *$ & $8.59 *$ & & $16.91^{*}$ & & $6.64 *$ & $5.84 *$ & & $11.72 *$ & \\
\hline & & V & $\mathrm{G}$ & & $\mathrm{V} \times \mathrm{G}$ & & V & $\mathrm{G}$ & & $\mathrm{V} \times \mathrm{G}$ & \\
\hline & & $8.42 *$ & $6.74 *$ & & $12.02 *$ & & $7.30 *$ & $4.60 *$ & & $9.41 *$ & \\
\hline
\end{tabular}


The results concerning to the effect of gamma rays applications revealed that, the pods weight/plant gradually decreased with increasing dose up to $50 \mathrm{Kr}$ compared with control Table (6). Moreover, the four genotypes in M2 gave high values than M1 generation under different gamma rays applications. Maximum pod weight/plant was recorded for the NC9 cultivar $(124.05 \mathrm{~g})$ followed by Gregory $(119.4 \mathrm{~g})$ in M1, while in M2 generation the highest values were recorded in the Gregory cultivar followed by NC9 and Runner, while Bold displayed the lowest values in both M1 and M2 for this trait. The interaction between gamma rays application and cultivars on pod weight/plant was shown in Table (6). The Gregory cultivar had the maximum values when it treated by 10 and $30 \mathrm{kr}$ while Bold was the lowest one than the others in both M1 and M2 generations. These results are similar with found by Animasaun et al. (2014), Muniappan et al. (2016), Gunasekaran and Pavadai (2015) and Kavera and Nadaf (2017).

\section{100-seed weight/plant}

Means of 100-seed weight/plant under field conditions for the studied cultivars under investigation treated with sodium azide and gamma rays in both generations are given in Table (7). Analysis of variance for all cultivars, mutantgens (Sodium azide and Gamma rays) and their interactions showed significant differences for 100-seed weight/plant in both M1 and M2 generations. For sodium azide, 100-seed weight/plant was gradually decreased significantly with increasing sodium azide concentration from 0.001 to 0.003 in M1 and M2 generation except NC9 at $0.001 \mathrm{~m}$ in M2 generation was increased than control. 100-seed weight/plant of all cultivars in the control conditions gave higher values (64.3and 66.4g) than 0.001 (61.8 and $64.6 \mathrm{~g})$ and 0.003 levels $(61.9$ and $65.9 \mathrm{~g})$ in $\mathrm{M} 1$ and M2 as shown in Table (9). Maximum values of 100- seed weight/plant were recorded for the Gregory cultivar (80.6) in M1 followed by NC9 (80.0), while the Runner and Bold cultivars displayed the lowest values of 100-seed weight/plant in M1generation. In M2 generation, the NC9 (84.7g) and Gregory (84.3g) cultivars gave high values as average of all sodium azide applications. Concerning to the effect of interaction between different cultivars and sodium azide applications on 100-seed weight, means of M1 and M2 generations indicated that Gregory and NC9 had the maximum values of 100- seed weight when they treated by $0.001 \mathrm{M}$ in M1 and M2 generations. The results concerning the effect of radiation doses applications revealed that, in M1 and M2 generations on 100-seed weight/plant gradually decreased with increasing dose from $10 \mathrm{kr}$ to $30 \mathrm{Kr}$ and increased at $50 \mathrm{kr}$ Table (7). High values of 100-seed weight/plant were recorded in Gregory cultivar (79.7and $81.9 \mathrm{~g}$ ) in M1 and M2, respectively followed by NC9 (76.6 and $80.3 \mathrm{~g})$ on the other hand, runner and Bold cultivars had the lowest values for this trait in both M1 and M2. The interaction between gamma rays treatments and cultivars on100-seed weight was shown in Table (7). Means of M1 and M2 generations indicated that NC9 and Gregory had the maximum values when they treated by $10 \mathrm{kr}, 50 \mathrm{Kr}$ and $30 \mathrm{kr}$ while Runner and Bold gave the lowest than others in both M1 and M2 generations.

It can be also noticed that average means of 100 seed weight affected significantly by sodium azide mutagen were higher than those affected by radiation mutagen in both generations. These results suggested that sodium azide mutagen may be more valid for improvement height of peanut than radiation mutagen. These results are similar with found by Animasaun et al. (2014), Muniappan et al. (2016) and Kavera and Nadaf (2017).

Table (7): Effect of Sodium azide and Gamma rays on 100-seed weight (g) for peanut cultivars at M1 and M2 generations

\begin{tabular}{|c|c|c|c|c|c|c|c|c|c|c|c|}
\hline & & \multicolumn{5}{|c|}{ M1 } & \multicolumn{5}{|c|}{ M2 } \\
\hline & & NC9 & Gregory & Bold & Runner & $\mathbf{X}$ & NC9 & Gregory & Bold & Runner & $\mathbf{X}$ \\
\hline \multirow{3}{*}{$\begin{array}{l}\text { Sodium } \\
\text { azide } \\
\text { (M) }\end{array}$} & Con. & 81.00 & 82.67 & 50.67 & 42.67 & 64.3 & 83.33 & 84.33 & 52.33 & 45.67 & 66.4 \\
\hline & 0.001 & 79.67 & 81.33 & 45.33 & 41.00 & 61.8 & 87.00 & 85.33 & 48.67 & 37.33 & 64.6 \\
\hline & 0.003 & 79.33 & 77.67 & 50.00 & 40.67 & 61.9 & 83.67 & 83.33 & 51.00 & 44.33 & 65.6 \\
\hline \multirow[t]{2}{*}{$X^{`}$} & & 80.0 & 80.6 & 48.7 & 41.4 & & 84.7 & 84.3 & 50.7 & 42.4 & 80.0 \\
\hline & Con. & 81.00 & 82.67 & 50.67 & 42.67 & 64.3 & 83.33 & 84.33 & 52.33 & 45.67 & 66.4 \\
\hline \multirow{3}{*}{$\begin{array}{l}\text { Gamma } \\
\text { rays } \\
(\mathbf{K r})\end{array}$} & $10 \mathrm{kr}$ & 79.67 & 75.67 & 50.33 & 42.67 & 62.1 & 81.67 & 80.33 & 52.67 & 42.33 & 64.3 \\
\hline & $30 \mathrm{kr}$ & 70.33 & 79.33 & 49.33 & 45.67 & 61.2 & 76.33 & 80.33 & 50.33 & 41.67 & 62.2 \\
\hline & $50 \mathrm{kr}$ & 75.33 & 81.00 & 52.00 & 46.33 & 63.7 & 79.67 & 82.67 & 49.00 & 45.00 & 64.1 \\
\hline \multicolumn{2}{|l|}{$\mathbf{X}^{\vee}$} & 76.6 & 79.7 & 50.6 & 44.3 & & 80.3 & 81.9 & 51.1 & 43.7 & 76.6 \\
\hline \multirow{4}{*}{\multicolumn{2}{|c|}{ L.S.D 5\% }} & $\mathrm{V}$ & $\mathrm{S}$ & & $\mathrm{V} \times \mathrm{S}$ & & $\mathrm{V}$ & $\mathrm{S}$ & & $\mathrm{V} \times \mathrm{S}$ & \\
\hline & & $1.09 *$ & $0.94 *$ & & $1.88 *$ & & $1.82 *$ & $1.50^{*}$ & & $3.01 *$ & \\
\hline & & V & $\mathrm{S}$ & & $\mathrm{V} \times \mathrm{S}$ & & V & S & & $\mathrm{V} \times \mathrm{S}$ & \\
\hline & & $2.10 *$ & $1.72 *$ & & $2.42 *$ & & $2.16^{*}$ & $1.78^{*}$ & & $3.60 *$ & \\
\hline
\end{tabular}




\section{Shelling percentage:}

The results in Table (8) showed mean values of shelling percentage in M1 and M2 generations. Analysis of variance for all cultivars, mutagens and their interactions showed significant differences for mean values of shelling percentage in both M1 and M2 generations. Concerning to sodium azide applications, mean values of shelling percentage were decreased with increasing concentration of sodium azide in M1 and M2 with values (71.44 and 51.04 ) and (72.66 and 59.38) compared with control (75.61 and 49.69) Table (8). With regards to cultivars, the NC9 cultivar recorded high values for shelling percentage (83.26 and $63.80 \%$ ) in $\mathrm{M} 1$ and $\mathrm{M} 2$, respectively followed by Gregory $(78.41 \%)$ in M1 and Bold in M2, while Runner displayed the lowest value for this trait in M1 and M2 as average of all sodium azide applications. Concerning to the effect of interaction between four cultivars and sodium azide applications for shelling percentage, the NC9 genotype had the highest values (83.55) when it treated with $0.001 \mathrm{M}$ in $\mathrm{M} 1$ and (80.16) in $0.003 \mathrm{M}$ in $\mathrm{M} 2$, while Runner and Bold were the lowest than others when they treated with 0.001 and $0.003 \mathrm{M}$ in $\mathrm{M} 1$ and $\mathrm{M} 2$ generations. The results in Table (8) revealed that the effect of gamma rays application for shelling percentage was decreased significantly with increasing gamma rays doses in M1 and M2 with values $68.54,65.66$ and $61.74 \%$ and, $51.30,48.45$ and 44.80 in $10 \mathrm{kr}, 30 \mathrm{kr}$ and $50 \mathrm{kr}$, respectively compared with control (75.61 and 49.69). About cultivars, the NC9 recorded high values for shelling percentage (63.18 and 60.14) followed by Bold (76.14 and 52.66) in M1 and M2, respectively. While Bold displayed the lowest values for this trait in M1 and M2 as average of all gamma rays doses. Concerning to the effect of interaction between cultivars and gamma rays for shelling percentage, the NC9 genotype had the highest values (74.48) and (73.38) when it treated with $10 \mathrm{kr}$ in $\mathrm{M} 1$ and M2, respectively, while Runner and Bold were the lowest than others when they treated with $10 \mathrm{kr}, 30 \mathrm{kr}$ and $50 \mathrm{kr}$ in M1 and M2 generations. These results were accepted with Cheong et al. (2004), Gunasekaran and Pavadai (2015).

Table (8): Effect of Sodium azide and Gamma rays on shelling percentage for peanut cultivars at M1 and M2 generations

\begin{tabular}{|c|c|c|c|c|c|c|c|c|c|c|c|}
\hline & & \multicolumn{5}{|c|}{ M1 } & \multicolumn{5}{|c|}{ M2 } \\
\hline & & NC9 & Gregory & Bold & Runner & $\mathbf{X}^{\prime}$ & NC9 & Gregory & Bold & Runner & $\mathbf{X}^{\times}$ \\
\hline \multirow{3}{*}{$\begin{array}{l}\text { Sodium } \\
\text { azide } \\
(\mathrm{M})\end{array}$} & Con. & 85.75 & 81.42 & 74.69 & 60.59 & 75.61 & 56.27 & 51.74 & 62.74 & 28.00 & 49.69 \\
\hline & 0.001 & 83.55 & 76.03 & 61.85 & 64.31 & 71.44 & 54.95 & 49.78 & 54.09 & 45.32 & 51.04 \\
\hline & 0.003 & 80.49 & 77.79 & 65.79 & 66.56 & 72.66 & 80.16 & 41.03 & 70.37 & 45.98 & 59.38 \\
\hline \multirow[t]{2}{*}{$\mathbf{X}^{`}$} & & 83.26 & 78.41 & 67.44 & 63.82 & & 63.80 & 47.52 & 62.40 & 39.77 & \\
\hline & Con. & 85.75 & 81.42 & 74.69 & 60.59 & 75.61 & 56.27 & 51.74 & 62.74 & 28.00 & 49.69 \\
\hline \multirow{3}{*}{$\begin{array}{l}\text { Gamma } \\
\text { rays } \\
(\mathbf{K r})\end{array}$} & $10 \mathrm{kr}$ & 74.48 & 62.61 & 69.31 & 67.76 & 68.54 & 57.38 & 45.97 & 60.29 & 41.57 & 51.30 \\
\hline & $30 \mathrm{kr}$ & 59.66 & 61.71 & 79.28 & 62.01 & 65.66 & 73.38 & 44.11 & 46.37 & 29.96 & 48.45 \\
\hline & $50 \mathrm{kr}$ & 55.39 & 73.09 & 79.83 & 38.65 & 61.74 & 49.66 & 49.92 & 51.32 & 28.31 & 44.80 \\
\hline \multicolumn{2}{|l|}{$\mathbf{X}^{\prime}$} & 63.18 & 65.81 & 76.14 & 56.14 & & 60.14 & 46.67 & 52.66 & 33.28 & \\
\hline \multirow{4}{*}{\multicolumn{2}{|c|}{ L.S.D 5\% }} & $\mathrm{V}$ & $S$ & & $\mathrm{~V} \times \mathrm{S}$ & & $\mathrm{V}$ & $S$ & & $\mathrm{~V} \times \mathrm{S}$ & \\
\hline & & $4.62 * *$ & $4.96^{* *}$ & & $8.20 * *$ & & $4.32 * *$ & $4.39^{*}$ & & $7.12 * *$ & \\
\hline & & $\mathrm{V}$ & G & & $\mathrm{V} \times \mathrm{G}$ & & V & G & & $\mathrm{V} \times \mathrm{G}$ & \\
\hline & & $7.87 * *$ & $4.95 * *$ & & $12.78 * *$ & & $5.61 * *$ & $5.54 *$ & & $10.19 * *$ & \\
\hline
\end{tabular}

\section{Seed yield/plant}

Mean performance of seed yield/plant under field conditions for the studied cultivars treated with sodium azide and gamma rays in both generations are given in Table (9). Analysis of variance for all cultivars, mutantgens (Sodium azide and Gamma rays) and their interactions showed significant differences for seed yield/plant in both M1 and M2 generations. For sodium azide, the seed yield/plant was decreased significantly with increasing sodium azide concentration from 0.001 to $0.003 \mathrm{~m}$ in M1 and M2 generations. Seed yield/plant of all cultivars in the control conditions was the higher values $(86.10$ and 65.75$)$ than $0.001 \mathrm{~m}$ (79.05 and
$56.63 \mathrm{~g})$ and $0.003 \mathrm{~m}(76.21$ and $53.88 \mathrm{~g})$ in $\mathrm{M} 1$ and M2, respectively as shown in Table (9). Maximum values of seed yield/plant was recorded for the NC9 (100.98 and 75.41g) followed by Gregory (96.78 and $65.53 \mathrm{~g}$ ) in both generations respectively. While Runner and Bold cultivars displayed the lowest values of seed yield /plant in M1andM2 generations. Concerning to the effect of interaction between different genotypes and sodium azide applications on seed yield/plant, means of M1 and M2 generations indicated that NC9 and Gregory had the maximum values of seed yield/plant when they treated by $0.001 \mathrm{~m}$ with values (99.32 and 72.50) followed by Gregory with values 
(94.58 and 66.91g) in M1 and M2 generations. The results concerning the effect of radiation doses applications revealed that, in M1 and M2 generations for seed yield/plant decreased also with increasing doses from $10 \mathrm{kr}$ to $50 \mathrm{kr}$ Table (9). High values of seed yield/plant were recorded in NC9 (84.98 and 74.41g) followed by Gregory ( 83.17 and $63.65 \mathrm{~g})$ in M1 and M2 respectively. On the other hand, Runner and Bold cultivars had the lowest values for this trait in both generations. The interaction between gamma rays treatments and cultivars on seed yield/plant was shown in Table (9), Mean performance of M1 and M2 generations indicated that NC9 and Gregory had the maximum values when they treated by $10 \mathrm{kr}, 30 \mathrm{Kr}$ and
$50 \mathrm{kr}$, while Runner and Bold were the lowest than others in both generations. From these results we can notice that the results of this trait in $\mathrm{M} 2$ are different from the results in M1 generation may due to more the segregation in M2 generation. It can be also, noticed that average of seed yield/plant affected significantly by radiation mutagen were higher than those affected by sodium azide mutagen in both generations. These results suggested that sodium azide mutagen may be more valid for improvement height of peanut than radiation mutagen. These findings are clearly also in 100 -seed weight. These findings were accepted by Muniappan et al. (2016), Kavera and Nadaf (2017) and Gemechis (2018).

Table (9): Effect of Sodium azide and Gamma rays on seed yield/plant ( $\mathrm{g}$ ) for peanut cultivars at M1 and M2 generations

\begin{tabular}{|c|c|c|c|c|c|c|c|c|c|c|c|}
\hline & & \multicolumn{5}{|c|}{ M1 } & \multicolumn{5}{|c|}{ M2 } \\
\hline & & NC9 & Gregory & Bold & Runner & $\mathbf{X}^{\prime}$ & NC9 & Gregory & Bold & Runner & $X^{\prime}$ \\
\hline \multirow{3}{*}{$\begin{array}{l}\text { Sodium } \\
\text { azide } \\
\text { (M) }\end{array}$} & Con. & 106.18 & 104.00 & 75.66 & 58.55 & 86.10 & 86.77 & 72.18 & 55.76 & 48.28 & 65.75 \\
\hline & 0.001 & 99.32 & 94.58 & 66.57 & 55.71 & 79.05 & 72.50 & 66.91 & 44.88 & 42.24 & 56.63 \\
\hline & 0.003 & 97.45 & 91.77 & 64.98 & 50.63 & 76.21 & 66.19 & 57.51 & 46.42 & 45.41 & 53.88 \\
\hline \multicolumn{2}{|l|}{$X^{\prime}$} & 100.98 & 96.78 & 69.07 & 54.96 & & 75.15 & 65.53 & 49.02 & 45.31 & \\
\hline \multirow{4}{*}{$\begin{array}{l}\text { Gamma } \\
\text { rays } \\
(\mathbf{K r})\end{array}$} & Con. & 106.18 & 104.00 & 75.66 & 58.55 & 86.10 & 86.77 & 72.18 & 55.76 & 48.28 & 65.75 \\
\hline & $10 \mathrm{kr}$ & 85.97 & 77.20 & 48.10 & 45.92 & 64.30 & 79.08 & 62.55 & 41.44 & 37.50 & 55.14 \\
\hline & $30 \mathrm{kr}$ & 76.42 & 76.77 & 45.88 & 44.07 & 60.79 & 69.10 & 60.27 & 39.66 & 33.88 & 50.73 \\
\hline & $50 \mathrm{kr}$ & 71.36 & 74.70 & 43.53 & 38.64 & 57.06 & 62.67 & 59.60 & 32.54 & 33.77 & 47.15 \\
\hline \multicolumn{2}{|l|}{$\mathbf{X}^{\top}$} & 84.98 & 83.17 & 53.29 & 46.80 & & 74.41 & 63.65 & 42.35 & 38.36 & \\
\hline \multirow{4}{*}{\multicolumn{2}{|c|}{ L.S.D 5\% }} & $\mathrm{V}$ & $\mathrm{S}$ & & $\mathrm{V} \times \mathrm{S}$ & & V & $\mathrm{S}$ & & $\mathrm{V} \times \mathrm{S}$ & \\
\hline & & $5.7 * *$ & $4.93 * *$ & & $9.87 * *$ & & $5.31 * *$ & $4.60 * *$ & & $9.20^{* *}$ & \\
\hline & & V & G & & $\mathrm{V} \times \mathrm{G}$ & & V & G & & $\mathrm{V} \times \mathrm{G}$ & \\
\hline & & $4.70 * *$ & $4.07 * *$ & & $8.14 * *$ & & $5.012 * *$ & $5.70 * *$ & & $9.13 * *$ & \\
\hline
\end{tabular}

\section{Leaf chlorophyll content (SPAD value)}

Analysis of variance for all cultivars, mutagens and their interactions showed significant differences for mean values of SPAD values in both M1 and M2 generations as presented in Table (10). Concerning to sodium azide doses, mean values of SPAD values were decreased with increasing concentration of sodium azide in M1 and M2 with values (31.09 and 28.83) and (33.68 and 31.58), respectively compared with control (37.67 and 40.04) as given in Table (10). With regards to cultivars, the NC9 cultivar recorded high values for SPAD values (36.18 and 38.92) in M1 and M2 respectively followed by Bold (32.33 and 34.71), while Runner displayed the lowest values for this trait in M1 and M2 as average of all sodium azide applications.

Concerning to the effect of interaction between cultivars and sodium azide applications for SPAD values, the NC9 genotype had the highest values (35.03) when it treated with $0.001 \mathrm{M}$ in M1 and (37.33) in $0.001 \mathrm{M}$ in $\mathrm{M} 2$, while Runner was the lowest than others when it treated with 0.001 and $0.003 \mathrm{M}$ in M1 and M2 generations.
The results concerning to the effect of gamma rays applications (Table 10) revealed that, mean values of SPAD were decreased significantly with increasing concentration of gamma rays doses in $\mathrm{M} 1$ and $\mathrm{M} 2$ with values (33.71, 32.59 and 28.14) and (36.33, 35.18 and $31.47)$ at $10 \mathrm{kr}, 30 \mathrm{kr}$ and $50 \mathrm{kr}$, respectively compared with control (37.67 and 40.04). About cultivars, in M1, the Bold cultivar recorded high values for SPAD values (34.04) followed by Gregory (33.73). While in M2 generation, all cultivars were very close to each other in terms of SPAD values under different doses of gamma rays as average of all.

Concerning to the effect of interaction between cultivars and gamma rays for SPAD values, the Gregory had the highest values (37.00) when it treated with $10 \mathrm{kr}$ in M1. On the other side, the genotype Bold had the highest value (37.47) in M2 generation, while Runner was the lowest than others when they treated with $20 \mathrm{kr}, 30 \mathrm{kr}$ and $50 \mathrm{kr}$ in M1 and M2 generations.

From these results, we noticed that the trait of total SPAD values was sensitive for mutagenic treatments. These results accepted with Bolbhat and Dhumal (2012), Kulkani and Mogle (2013), Mishra et al. (2013), Kamble and Patil (2014). 
Table (10): Effect of Sodium azide and Gamma rays on Leaf chlorophyll content (SPAD value) for peanut cultivars at M1 and M2 generations

\begin{tabular}{|c|c|c|c|c|c|c|c|c|c|c|c|}
\hline & & \multicolumn{5}{|c|}{ M1 } & \multicolumn{5}{|c|}{ M2 } \\
\hline & & NC9 & Gregory & Bold & Runner & $X^{\prime}$ & NC9 & Gregory & Bold & Runner & $\mathbf{X}^{\top}$ \\
\hline \multirow{4}{*}{$\begin{array}{l}\text { Sodium } \\
\text { azide } \\
\text { (M) } \\
\mathrm{X}^{\prime}\end{array}$} & Con. & 41.4 & 37.07 & 35.93 & 36.27 & 37.67 & 44.27 & 38.73 & 37.47 & 39.67 & 40.04 \\
\hline & 0.001 & 35.03 & 30.87 & 30.57 & 27.9 & 31.09 & 37.33 & 33.33 & 33.33 & 30.73 & 33.68 \\
\hline & 0.003 & 32.1 & 27.2 & 30.5 & 25.53 & 28.83 & 35.17 & 29.07 & 33.37 & 28.7 & 31.58 \\
\hline & & 36.18 & 31.71 & 32.33 & 29.90 & & 38.92 & 33.71 & 34.72 & 33.03 & \\
\hline \multirow{4}{*}{$\begin{array}{l}\text { Gamma } \\
\text { rays } \\
\text { (Kr) }\end{array}$} & Con. & 41.40 & 37.07 & 35.93 & 36.27 & 37.67 & 44.27 & 38.73 & 37.47 & 39.67 & 40.04 \\
\hline & $10 \mathrm{kr}$ & 33.20 & 37.00 & 34.20 & 30.50 & 33.71 & 36.73 & 35.73 & 37.47 & 35.4 & 36.33 \\
\hline & $30 \mathrm{kr}$ & 31.80 & 32.00 & 33.30 & 33.02 & 32.59 & 36.87 & 34.53 & 34.70 & 34.60 & 35.18 \\
\hline & $50 \mathrm{kr}$ & 24.70 & 28.90 & 32.70 & 26.30 & 28.14 & 27.73 & 34.40 & 33.33 & 30.40 & 31.47 \\
\hline \multicolumn{2}{|l|}{$\mathbf{X}^{\top}$} & 32.77 & 33.73 & 34.04 & 31.57 & & 36.40 & 35.85 & 35.74 & 35.02 & \\
\hline \multirow{4}{*}{\multicolumn{2}{|c|}{ L.S.D 5\% }} & $\mathrm{V}$ & $\bar{S}$ & & $\mathrm{~V} \times \mathrm{S}$ & & $\mathrm{V}$ & $S$ & & $\mathrm{~V} \times \mathrm{S}$ & \\
\hline & & $1.94 *$ & $1.31 *$ & & $2.05 *$ & & $0.31 *$ & $0.27 *$ & & $3.54 *$ & \\
\hline & & V & $\mathrm{S}$ & & $\mathrm{V} \times \mathrm{S}$ & & V & $\mathrm{S}$ & & $\mathrm{V} \times \mathrm{S}$ & \\
\hline & & $2.01 *$ & $1.16^{*}$ & & $2.3 *$ & & $0.74 *$ & $0.57 *$ & & $2.86^{*}$ & \\
\hline
\end{tabular}

\section{Seed oil content (\%)}

Results belonging to seed oil content for the four peanut cultivars as affected by sodium azide and gamma radiation applications for both generations are given in Table (11)

The analysis of variance indicated that, varietal differences, mutagen doses, and their interaction were significant in M1 and M2 generations except for sodium azide in M1 generation.

The means indicated that, over all varieties, seed oil content was increased by sodium azide application in M2 generations than control. Furthermore, over all sodium azide treatments, seeds of Bold cultivar were higher in their oil content compared to the other three cultivars in the first generation. While in the second generation, the runner and Gregory had the highest values for this trait. In addition, the pattern response of the four cultivars differs in relation to concentration application in both generations. As in the first generation, the cultivars Bold and Runner produced their maximum seed oil content when they treated by 0.003 and $0.001 \mathrm{M}$, respectively. In the second generation, the cultivars Runner and Gregory produced their highest seed oil content from 0.003and NC9 under $0.01 \mathrm{M}$. Concerning to the effect of gamma rays applications results were revealed that, mean values of oil content were increased significantly with increasing concentration of gamma rays doses in M1 and M2 with values $(46.9,48.3$ and $48.7 \%)$ and $(51.0,51.3$ and $51.2 \%$ ) at $10 \mathrm{kr}, 30 \mathrm{kr}$ and $50 \mathrm{kr}$, respectively compared with control (47.6 and 49.9\%) (Table.11). The Bold cultivar recorded high values for oil percentage (50.32) followed by Runner (49.04\%) in M1. While in M2 generation, all cultivars were very close to each other in terms of oil percentage under different doses of gamma rays as average of all with values $51.19,50.79,50.73$ and $50.65 \%$ ). Concerning to The effect of interaction between cultivars and gamma rays for oil percentage, The Bold cultivar had the highest values $51.34 \%$ and $50.39 \%$ and runner cultivar with values $49.02 \%$ and $49.66 \%$ of oil percentage, when they treated with $50 \mathrm{kr}$ and $30 \mathrm{kr}$ in M1 generation respectively. On the other side, the Gregory cultivar had the highest value $52.45 \%$ under $50 \mathrm{kr}, 52.0 \%$ under $30 \mathrm{kr}$ in $\mathrm{M} 2$ generation. Finally, plants affected by gamma radiation showed a slight increase in seed oil content compared to those affected by sodium azide in both generations. Favorable effects on seed oil content as a result of using different mutagens were reported by Tingting et al. (2020).

Table (11): Effect of Sodium azide and Gamma rays on Seed oil content (\%) for peanut cultivars at M1 and M2 generations

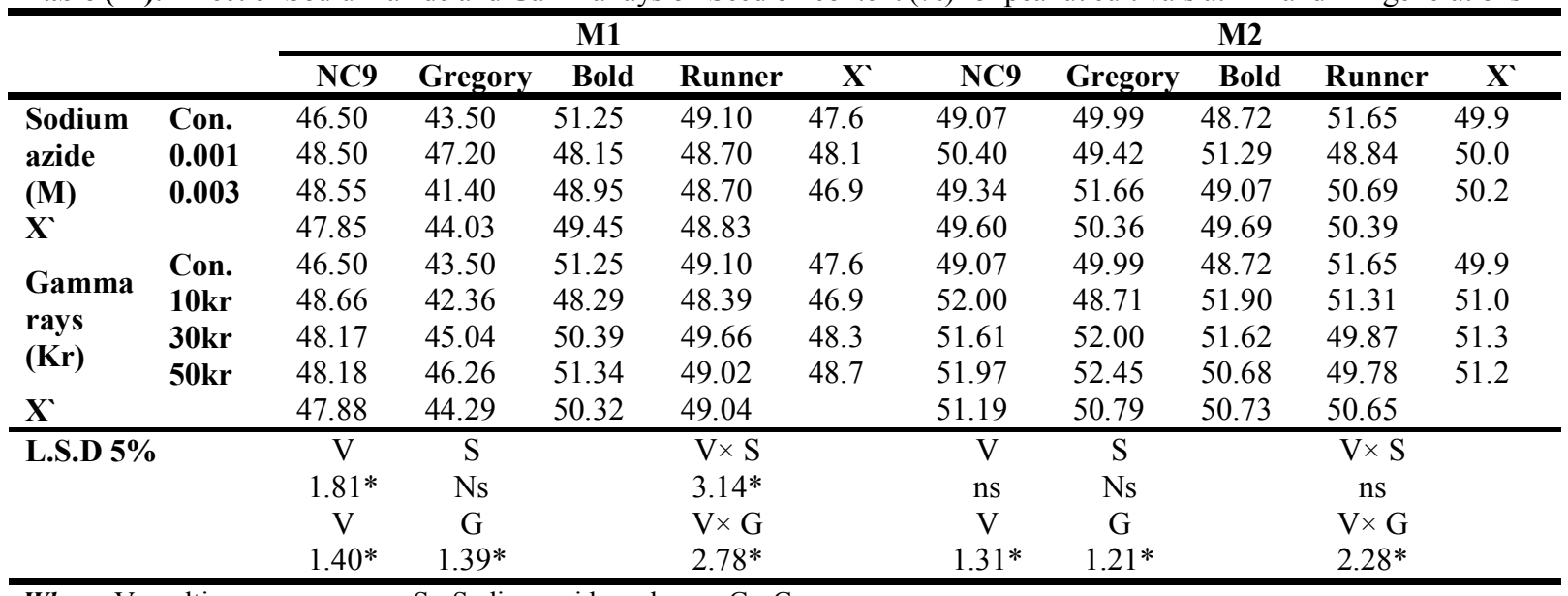

Where, V= cultivars;

$\mathrm{S}=$ Sodium azide and

$\mathrm{G}=$ Gamma rays 


\section{II-Genetic variability for nine variables in four peanut cultivars under different mutagens: Days to flowering}

The values of genotypic and phenotypic variance were higher in most studied varieties under gamma rays than sodium azide in M1 and M2 generation (Table.12). In addition, the values of phenotypic ranged in M1 generation from 3.12 for Bold to 52.77 for NC9 under sodium azide. However, in M2 generation Bold cultivar had the same low amount of phenotypic variance (6.50) under gamma rays while, the highest amount (32.20) was obtained from Gregory under gamma rays. Moreover, values of genotypic variance varied from 1.92 for Bold to 50.0 for NC9 under sodium azide in M1 generation and from 4.34 (Bold) to 19.70 (Gregory) under gamma rays in M2 generation. The studied cultivars, which exhibited amount of genotypic variance, could be considered adequate for improving this trait in breeding programs. Furthermore, values of phenotypic variance were more than genotypic ones in all studied varieties during the two generations. The values of phenotypic coefficient of variation ranged in M1 generations from $0.04 \%$ for Bold to $0.20 \%$ for NC9 under sodium azide. Moreover, in M2 generation PCV varied from $0.05 \%$ for Bold to $0.16 \%$ for Runner under gamma rays. For $\mathrm{GCV}$, values ranged from $0.03 \%$ for Bold to $0.20 \%$ for NC9 under sodium azide in M1 generation. Moreover, in M2 generation GCV varied from $0.04 \%$ for Bold to $0.11 \%$ for Runner under gamma rays. The heritability estimates, it was noticed that the four varieties in both generations gave higher values under gamma rays than sodium azide except for NC9 in M1 and Bold in M2 generation. Heritability estimates ranged in M1 generation from 58.06\% for Gregory under sodium azide to $94.75 \%$ for NC9 also under sodium azide. Moreover, it's varied in M2 generation from $38.46 \%$ for Runner under sodium azide to $78.89 \%$ for NC9 under gamma rays. Most heritability estimates in both generations ranged from moderate to high indicating that a relatively large portion of the phenotypic variability was due to genetic causes. Finally, from the above-mentioned results it could be concluded that, the studied varieties differ in their response to each mutagen. This may be due to differential mutagen-sensitivity among the cultivars (Gunasekaran and Pavadai, 2015).

\section{Number of primary branches/plant}

The phenotypic variance of branches number/plant was higher than genotypic variance in both mutagens in both generations in Table (12). Values of phenotypic variance ranged from 1.44 for Runner under sodium azide to 35.12 for Bold under gamma rays. However, in M2 generation Runner had the lowest amount of phenotypic variance $(0.55)$ under sodium azide while, the highest amount (11.78) was obtained from Gregory under gamma rays. Moreover, values of genotypic variance varied from 1.00 for Runner under sodium azide to 22.97 for Bold under gamma rays in M1 generation. On the other side, in M2 generation $\mathrm{Vg}$ varied from $0.24 \%$ for Runner to $10.53 \%$ for Gregory under sodium azide. Considering the phenotypic coefficients of variation, values ranged in M1 generation from $0.13 \%$ for NC9 under sodium azide to $0.48 \%$ for Bold under gamma rays. Moreover, in M2 generation PCV varied from $0.09 \%$ for Runner to $0.26 \%$ for Gregory under gamma rays. For GCV, values ranged from $0.09 \%$ for NC9 under sodium azide to $0.39 \%$ for Bold under gamma rays in M1 generation. But, in M2 generation GCV varied from $0.06 \%$ for Bold under sodium azide to $0.25 \%$ for Gregory under gamma rays. The heritability estimates scored moderate value (46.03) for Runner and high value (92.41) was recorded for NC9 under gamma rays in M1 generation. In M2 generation, heritability estimates varied from 25.71 for NC9 to 96.78 for Gregory under sodium azide. High value of expected genetic advance was recorded by Gregory under sodium azide (6.58). While the lowest value (0.97) was obtained from Runner under sodium azide. These results indicated non-additive gene action predominance, which could be exploited through heterosis breeding these results agreements with Mensah and Obadoni (2007) referred to characters with high heritability can therefore be improved rapidly through selection than those with low heritability, since the latter are influenced by environmental factors in peanut.

\section{Plant height}

The values in Table (12), of Vp for plant height, ranged from 61.54 for NC9 under gamma rays to 836.44 for Runner under sodium azide. However, in M2 generation Bold had the lowest amount of phenotypic variance 40.50 under sodium azide. While, the highest amount 668.49 was obtained from Runner under sodium azide. Moreover, the values of genotypic variance $(\mathrm{Vg})$ varied from 21.09 to 469.44 and from 20.19 to 534.69 for NC9 and Runner under gamma rays and sodium azide in M1and M2 generation, respectively. The PCV, values ranged from $0.09 \%$ to $0.41 \%$ and from $0.70 \%$ to $0.33 \%$ for Bold and Runner under sodium azide in both generations respectively. Moreover, for GCV, In M1 and M2 the results indicate that the values of this parameter take the same trend of the results of PCV. Heritability was showed low value of for NC9 and Runner under gamma rays $(34.27,37.20 \%)$ and high values for NC9 genotype (84.03, 84.41\%) under sodium azide in M1 and M2 generation, respectively. Concerning to expected genetic advance, the high value was recorded by Runner cultivar under sodium azide followed by Gregory under sodium azide. It revealed that non-additive gene action was involved for expression of this trait in M1 and M2, May due to an increase of homozygosis of genes involves (Wani and Khan, 2006). Similar results were also reported by Badigannavar and Murty (2007), they concluded that high heritability when coupled with high genetic advance for plant height in peanut in M2 generation, it might be due to additive gene and this trait could be effectively in next generation.

\section{Yield and Yield components:}

\section{1- Number of pods / plant:}

Table (13) shows the genetic parameters for number of pods / plant. In M1 and M2, the results indicate that the values of genotypic and phenotypic 
variance at gamma rays doses were higher than the values of sodium azide. Also, it showed that genotypic variance have great part of phenotypic variance at gamma rays in two generations and more than at sodium azide. This may due to the effect of gamma rays caused great variation on the genetic level of this trait and this variation can pass from parents to their progenies. These results accepted with Mensah and B. Obadoni (2007) in peanut (Arachis hypogaea L. CV SS1145B and RMP 91). Considering the phenotypic coefficients of variation, values ranged in M1 generation from $0.14 \%$ for NC9 under sodium azide to $0.29 \%$ for Bold under gamma rays. Moreover, in M2 generation PCV varied from $0.11 \%$ for Gregory to $0.23 \%$ for Bold under sodium azide. The values of GCV ranged from $0.12 \%$ for NC9 under sodium azide to $0.28 \%$ for Bold under gamma rays in M1 generation. Moreover, in M2 generation $\mathrm{GCV}$ varied from $0.8 \%$ for $\mathrm{NC} 9$ to $0.23 \%$ for Bold under gamma rays. The results of this trait showed moderate value of heritability (55.24) for NC9 and high value (95.62) was recorded for Bold under gamma rays in M1 generation followed by Gregory (94.6). In M2 generation, heritability estimates varied from 32.38 for NC9 under sodium azide to 97.63 for Bold under gamma rays. Respecting to expected genetic advance, the high value was recorded by Gregory cultivar followed by NC9 under Gamma rays. While the lowest value (3.53) was obtained from Bold under Gamma rays. These results indicated to non-additive gene action predominance, which could be exploited Reddy et al. (2017) and Shankar et al. (2018).

\section{2- Pods yield / plant:}

The results showed that values of $\mathrm{Vp}$, and $\mathrm{Vg}$, $\mathrm{PCV}$ and GVC at gamma rays were more than the values at sodium azide in both generations for pods yield / plant in all generations at different mutagenic treatments (Table 13). The results of this trait was showed moderate value of heritability (42.71) for NC9 cultivar and high value (96.35) was recorded for Gregory under gamma rays in M1 generation followed by Bold cultivar (96.19). In M2 generation, heritability estimates were varied from $49.98 \%$ for Gregory under sodium azide to $95.47 \%$ for Runner under gamma rays. The expected genetic advance was recorded high value by Gregory cultivar followed by Bold under both mutagens. While, the lowest value (5.63) was obtained from Gregory under sodium azide, these results indicated non-additive gene action predominance and high heritability may not necessary lead to increased genetic gain unless sufficient genetic variability existed in the germplasm. These results are confirmed with Babariya and Dobariya (2012), Ashutosh et al. (2016) Thirumala Rao (2016) and Rajarathinam et al. (2017).

\section{3-100-Seed weight:}

Table (13) showed the genetic parameters for 100 -seed weight. at gamma rays were more than the values at sodium azide in both generations (except for Bold under gamma rays) (Table 13). The genotypic variance at gamma rays and at sodium azide concentrations take major part of phenotypic variance that mean the two treatments have great effect on genotype of this trait. Heritability estimated was showed moderate value $(59.50 \%)$ for Bold and high value (99.20) was recorded for NC9under gamma rays in M1 generation. In M2 generation, heritability estimates varied from $66.67 \%$ for Gregory under sodium azide to $96.94 \%$ for Gregory under gamma rays. High value of expected genetic advance was recorded by Runner cultivar (14.97). While the lowest value (2.38) was obtained from Gregory under sodium azide for 100-seed weight. These results indicated that gamma rays doses effect on this trait by additive gene action and this genetic variation transmit from the parents to progeny, also this trait at this treatments can easy be fixed in the genotypes by the selection in early generation. These results are confirmed with Kyaw et al. (2017), Reddy et al. (2017), and Shankar et al. (2018), refer to insure that selection for high yield is more effective if based on these characters in pea and the importance of additive genetic action.

\section{4-Seeds yield / plant}

The values of phenotypic and genotypic variance at sodium azide were higher than gamma rays doses except Vp in Runner at M1 for seed yield / plant. While in M2, the values of phenotypic variance at gamma rays were higher than sodium azide. Thus, increased variation for seed yield/plant has been induced in peanut cultivars. The values of phenotypic coefficients of variation, ranged in $\mathrm{M} 1$ generation from $0.16 \%$ for $\mathrm{NC} 9$ and Gregory under gamma rays to $0.56 \%$ for Gregory under sodium azide. Moreover, in M2 generation PCV varied from $0.07 \%$ for Gregory sodium azide to $0.34 \%$ for Runner under gamma rays. For GCV, values ranged from $0.13 \%$ for NC9 under gamma rays to $0.50 \%$ for Gregory under sodium azide in M1 generation. Moreover, in M2 generation GCV varied from $0.04 \%$ for Gregory under sodium azide to $0.30 \%$ for Runner under gamma rays. Kavera and Nadaf (2017), reported that the radiated soybean plants showed moderate GCV for seed yield/plant in both M2 and M3 generations. While, Habtamu (2016) who exposed seeds of soybean varieties with different doses of gamma rays found that high level of GCV for seed yield/plant. As well as, increased coefficient of variation for seed yield/plant has been induced in peanut and sesame (Tingting et al., 2020). Respecting to heritability, the results of this trait showed low value of heritability (33.67\%) for Runner under gamma rays and high value (89.18\%) was recorded for Gregory under gamma rays in M1 generation. In M2 generation, heritability estimates varied from $33.67 \%$ to $97.19 \%$ for Bold under sodium azide and gamma rays, respectively. In this concern, increased heritability estimates for seed yield/plant has been induced in peanut (Thirumala Rao et al., 2014; Kashid and More, 2016; Kavera and Nadaf, 2017; Habtamu, 2016). Respecting to expected genetic advance, the high value was recorded by NC9 cultivar (46.49) followed by Gregory (31.90) under gamma rays. While the lowest value (5.01) was obtained from Gregory under sodium azide.

\section{5- Oil percent (\%):}

The values of phenotypic and genotypic variance oil percentage at sodium azide were higher than those obtained by gamma rays doses except $\mathrm{Vp}$ in Bold 
cultivars. While in M2, the values of phenotypic and genotypic variance were higher in Gregory and runner under sodium azide than in case of gamma rays while, the cultivars $\mathrm{NC} 9$ and Bold the values for $\mathrm{Vp}$ and $\mathrm{Vg}$ were higher under sodium azide than gamma rays (Table 14). The phenotypic and genotypic coefficients of variation, scored the lowest values were recorded inNC9 and the high values were recorded in Runner under sodium azide and gamma rays in both generations.

Regarding to Heritability, the results of this trait was showed moderate value of heritability $(53.818 \%)$ for NC9 under gamma rays and high value (76.699\%) was recorded for Gregory under sodium azide in M1 generation. While in M2 generation, heritability estimates varied from $56.11 \%$ for Gregory to $75.88 \%$ for Bold under Gamma rays. Expected genetic advance, was recorded high value by Runner cultivar (4.400) followed by Bold. While the lowest value (2.065) was obtained from Gregory under Gamma rays. These findings may be due to differential mutagen-sensitivity among the varieties. These results are in agreement with Lopez et al. (2001), Channayya et al. (2011) and Tingting et al. (2020).

\section{6- Leaf chlorophyll content (SPAD value):}

The values of genotypic and phenotypic variance of gamma rays doses were more than the values of sodium azide (Table 14), where ranged from 5.27 for Runner under sodium azide to 318.59 for NC9 under gamma rays. However, in M2 generation Bold had the lowest amount of phenotypic variance (22.66) while, the highest amount (73.43) was obtained for Gregory under gamma rays. Moreover, values of genotypic variance varied from 2.16 for Runner under sodium azide to $231.35 \%$ for NC9 under gamma rays in M1 generation. On the other side, in M2 generation Vg varied from $15.01 \%$ for Bold under sodium azide to $70.42 \%$ for Gregory under gamma rays. The phenotypic and genotypic coefficients of variation, values ranged in M1 generation from $0.09 \%$ to $0.59 \%$ and from $0.06 \%$ to 0.50 $\%$ for Runner under sodium azide and NC9 under gamma rays, respectively. Moreover, in M2 generation PCV varied from $0.13 \%$ for Bold under gamma rays to $0.25 \%$ for Gregory under sodium azide. For GCV, the same trend was found in PCV values ranged from 0.11 $\%$ for Bold under gamma rays to $0.24 \%$ for Gregory under sodium azide in M2 generation. Concerning heritability, the results of this trait showed moderate value of heritability $(40.99 \%)$ for runner under sodium azide and high value $(95.43 \%)$ was recorded for NC9 under sodium azide in M1 generation. In M2 generation, heritability estimates varied from 47.73 for Runner to 96.79 for Gregory under sodium azide.

Table (12): Effect of Sodium azide and Gamma rays on genetic variability for days to flowering, number of primary branches/plant and plant height at M1 and M2 generations

\begin{tabular}{|c|c|c|c|c|c|c|c|c|c|c|c|c|c|}
\hline \multirow{2}{*}{ Traits } & \multirow{2}{*}{ Cultivars } & \multirow{2}{*}{ Muta. } & $\mathbf{V p}$ & Vg & P.C.V & G.C.V & $h^{2} \%$ & $\mathbf{V p}$ & $\mathbf{V g}$ & P.C.V & G.C.V & $h^{2} \%$ & GA \\
\hline & & & \multicolumn{5}{|c|}{ M1 } & \multicolumn{6}{|c|}{ M2 } \\
\hline \multirow{8}{*}{ 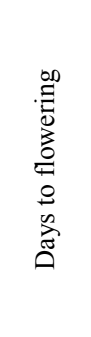 } & \multirow{2}{*}{ NC9 } & S.azide & 52.77 & 50.00 & 0.20 & 0.20 & 94.75 & 18.00 & 11.00 & 0.10 & 0.08 & 61.11 & 5.34 \\
\hline & & G. rays & 19.41 & 17.33 & 0.13 & 0.12 & 89.28 & 15.63 & 12.33 & 0.10 & 0.09 & 78.89 & 6.42 \\
\hline & \multirow{2}{*}{ Gregory } & S. azide & 15.50 & 9.00 & 0.09 & 0.07 & 58.06 & 19.00 & 12.00 & 0.10 & 0.08 & 63.16 & 5.67 \\
\hline & & G. rays & 18.00 & 11.00 & 0.10 & 0.08 & 61.11 & 32.20 & 19.70 & 0.12 & 0.09 & 61.18 & 7.15 \\
\hline & \multirow{2}{*}{ Bold } & S. azide & 3.12 & 1.92 & 0.04 & 0.03 & 61.54 & 16.00 & 9.00 & 0.09 & 0.07 & 56.25 & 4.64 \\
\hline & & G. rays & 6.35 & 4.13 & 0.06 & 0.05 & 65.04 & 6.50 & 4.37 & 0.05 & 0.04 & 67.23 & 3.53 \\
\hline & \multirow{2}{*}{ Runner } & S. azide & 14.50 & 8.80 & 0.13 & 0.10 & 60.69 & 13.00 & 5.00 & 0.13 & 0.08 & 38.46 & 2.86 \\
\hline & & G. rays & 16.00 & 10.00 & 0.13 & 0.10 & 62.50 & 23.00 & 12.00 & 0.16 & 0.11 & 52.17 & 5.15 \\
\hline \multirow{8}{*}{ 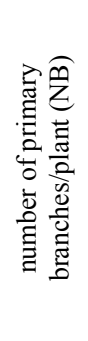 } & \multirow{2}{*}{ NC9 } & S. azide & 3.11 & 1.61 & 0.13 & 0.09 & 51.77 & 3.15 & 0.81 & 0.13 & 0.07 & 25.71 & 0.94 \\
\hline & & G. rays & 6.32 & 5.84 & 0.19 & 0.18 & 92.41 & 7.74 & 6.07 & 0.21 & 0.19 & 78.42 & 4.49 \\
\hline & \multirow{2}{*}{ Gregory } & S. azide & 16.00 & 8.00 & 0.29 & 0.20 & 50.00 & 10.88 & 10.53 & 0.23 & 0.23 & 96.78 & 6.58 \\
\hline & & G. rays & 14.70 & 13.25 & 0.27 & 0.25 & 90.14 & 11.78 & 10.52 & 0.26 & 0.25 & 89.30 & 6.31 \\
\hline & \multirow{2}{*}{ Bold } & S. azide & 8.11 & 5.00 & 0.23 & 0.18 & 61.65 & 3.53 & 1.61 & 0.15 & 0.10 & 45.61 & 1.77 \\
\hline & & G. rays & 35.12 & 22.97 & 0.48 & 0.39 & 65.40 & 3.78 & 1.36 & 0.16 & 0.10 & 35.98 & 1.44 \\
\hline & \multirow{2}{*}{ Runner } & S. azide & 1.44 & 1.00 & 0.15 & 0.13 & 69.44 & 0.55 & 0.24 & 0.09 & 0.06 & 43.64 & 0.67 \\
\hline & & G. rays & 4.28 & 1.97 & 0.23 & 0.15 & 46.03 & 3.45 & 1.59 & 0.19 & 0.13 & 46.09 & 1.76 \\
\hline \multirow{8}{*}{ 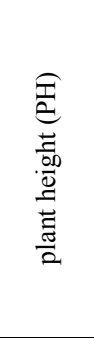 } & \multirow{2}{*}{ NC9 } & S. azide & 152.33 & 128.00 & 0.15 & 0.14 & 84.03 & 62.08 & 52.40 & 0.09 & 0.09 & 84.41 & 13.70 \\
\hline & & G. rays & 61.54 & 21.09 & 0.10 & 0.06 & 34.27 & 54.27 & 20.19 & 0.09 & 0.06 & 37.20 & 5.65 \\
\hline & \multirow{2}{*}{ Gregory } & S. azide & 293.44 & 241.83 & 0.23 & 0.21 & 82.41 & 51.42 & 31.08 & 0.09 & 0.07 & 60.44 & 8.93 \\
\hline & & G. rays & 74.26 & 33.08 & 0.11 & 0.07 & 44.55 & 143.32 & 104.24 & 0.15 & 0.13 & 72.73 & 17.94 \\
\hline & \multirow{2}{*}{ Bold } & S. azide & 63.00 & 25.00 & 0.09 & 0.06 & 39.68 & 40.50 & 25.54 & 0.07 & 0.06 & 63.06 & 8.27 \\
\hline & & G. rays & 73.00 & 55.70 & 0.10 & 0.08 & 76.30 & 46.47 & 27.37 & 0.08 & 0.06 & 58.90 & 8.27 \\
\hline & \multirow{2}{*}{ Runner } & S. azide & 836.44 & 469.44 & 0.41 & 0.30 & 56.12 & 668.49 & 534.69 & 0.33 & 0.29 & 79.98 & 42.60 \\
\hline & & G. rays & 171.40 & 75.40 & 0.15 & 0.10 & 43.99 & 93.55 & 25.15 & 0.11 & 0.06 & 26.88 & 5.36 \\
\hline
\end{tabular}


Table (13): Effect of Sodium azide and Gamma rays on genetic variability for number of pods/plant, pod yield/plant and 100-seed weight at M1and M2 generations

\begin{tabular}{|c|c|c|c|c|c|c|c|c|c|c|c|c|c|}
\hline \multirow{2}{*}{ Traits } & \multirow{2}{*}{ Cultivars } & \multirow{2}{*}{ Muta. } & $V p$ & Vg & P.C.V & G.C.V & $h^{2} \%$ & $V p$ & Vg & P.C.V & G.C.V & $h^{2} \%$ & GA \\
\hline & & & \multicolumn{5}{|c|}{ M1 } & \multicolumn{6}{|c|}{ M2 } \\
\hline \multirow{7}{*}{ 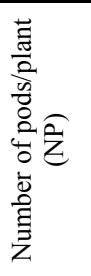 } & \multirow{2}{*}{ NC9 } & S. azide & 54.11 & 35.00 & 0.14 & 0.12 & 64.68 & 64.63 & 20.93 & 0.14 & 0.08 & 32.38 & 5.36 \\
\hline & & G. rays & 59.31 & 32.76 & 0.16 & 0.13 & 55.24 & 91.74 & 54.50 & 0.18 & 0.14 & 59.41 & 11.72 \\
\hline & \multirow{2}{*}{ Gregory } & S. azide & 91.00 & 80.00 & 0.16 & 0.15 & 87.91 & 57.23 & 48.83 & 0.11 & 0.10 & 85.32 & 13.30 \\
\hline & & G. rays & 107.40 & 101.60 & 0.18 & 0.17 & 94.60 & 84.53 & 71.53 & 0.13 & 0.12 & 84.62 & 16.03 \\
\hline & \multirow{2}{*}{ Bold } & S. azide & 179.11 & 136.17 & 0.24 & 0.21 & 76.03 & 138.10 & 92.40 & 0.19 & 0.15 & 66.91 & 16.20 \\
\hline & & G. rays & 226.90 & 216.97 & 0.29 & 0.28 & 95.62 & 201.80 & 197.01 & 0.23 & 0.23 & 97.63 & 28.57 \\
\hline & \multirow[t]{2}{*}{ Runner } & S. azide & 566.77 & 443.66 & 0.25 & 0.22 & 78.28 & 532.20 & 463.10 & 0.22 & 0.20 & 87.02 & 41.35 \\
\hline \multirow{9}{*}{ 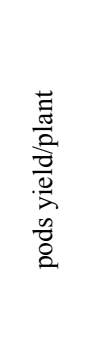 } & & G. rays & 805.35 & 343.95 & 0.29 & 0.19 & 42.71 & 844.70 & 435.68 & 0.27 & 0.19 & 51.58 & 30.88 \\
\hline & \multirow{2}{*}{ NC9 } & S. azide & 257.83 & 184.83 & 0.14 & 0.12 & 71.69 & 4032.10 & 3565.10 & 0.52 & 0.49 & 88.42 & 115.66 \\
\hline & & G. rays & 580.07 & 241.27 & 0.18 & 0.13 & 41.59 & 1931.02 & 1733.69 & 0.34 & 0.33 & 89.78 & 81.27 \\
\hline & \multirow{2}{*}{ Gregory } & S. azide & 76.77 & 39.00 & 0.07 & 0.05 & 50.80 & 29.85 & 14.92 & 0.04 & 0.03 & 49.98 & 5.63 \\
\hline & & G. rays & 380.30 & 366.41 & 0.16 & 0.16 & 96.35 & 249.70 & 229.95 & 0.12 & 0.11 & 92.09 & 29.98 \\
\hline & \multirow{2}{*}{ Bold } & S. azide & 378.77 & 309.33 & 0.28 & 0.25 & 81.67 & 424.11 & 339.14 & 0.26 & 0.23 & 79.97 & 33.92 \\
\hline & & G. rays & 443.00 & 426.11 & 0.32 & 0.31 & 96.19 & 466.30 & 445.16 & 0.28 & 0.28 & 95.47 & 42.47 \\
\hline & Runner & S. azide & 310.33 & 210.33 & 0.20 & 0.17 & 67.78 & 316.22 & 202.24 & 0.17 & 0.14 & 63.96 & 23.43 \\
\hline & & G. rays & 845.24 & 537.44 & 0.35 & 0.28 & 63.58 & 855.60 & 217.80 & 0.97 & 0.96 & 96.94 & 288.40 \\
\hline \multirow{8}{*}{ 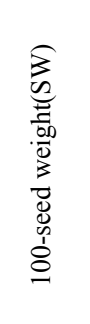 } & \multirow{2}{*}{ NC9 } & S. azide & 2.33 & 1.67 & 0.02 & 0.02 & 71.67 & 12.33 & 11.17 & 0.04 & 0.04 & 90.59 & 6.55 \\
\hline & & G. rays & 72.66 & 72.08 & 0.11 & 0.11 & 99.20 & 27.19 & 26.00 & 0.06 & 0.06 & 95.62 & 10.27 \\
\hline & \multirow{2}{*}{ Gregory } & S. azide & 20.11 & 16.67 & 0.06 & 0.05 & 82.89 & 3.00 & 2.00 & 0.02 & 0.02 & 66.67 & 2.38 \\
\hline & & G. rays & 26.88 & 24.41 & 0.07 & 0.06 & 90.81 & 11.41 & 9.50 & 0.04 & 0.04 & 83.26 & 5.79 \\
\hline & \multirow{2}{*}{ Bold } & S. azide & 25.33 & 23.67 & 0.10 & 0.10 & 93.45 & 10.33 & 9.67 & 0.06 & 0.06 & 93.61 & 6.20 \\
\hline & & G. rays & 3.63 & 2.16 & 0.04 & 0.03 & 59.50 & 8.97 & 8.00 & 0.06 & 0.06 & 89.19 & 5.50 \\
\hline & \multirow{2}{*}{ Runner } & S. azide & 3.44 & 3.00 & 0.04 & 0.04 & 87.21 & 60.11 & 56.34 & 0.18 & 0.18 & 93.73 & 14.97 \\
\hline & & G. rays & 18.97 & 18.50 & 0.10 & 0.10 & 97.52 & 11.55 & 10.00 & 0.08 & 0.07 & 86.58 & 6.06 \\
\hline
\end{tabular}

Table (14): Effect of Sodium azide and Gamma rays on genetic variability for seed yield/plant, seed oil content and Leaf chlorophyll content (SPAD value): for peanut varieties at M1and M2 generations

\begin{tabular}{|c|c|c|c|c|c|c|c|c|c|c|c|c|c|}
\hline \multirow{2}{*}{$\begin{array}{c}\text { Trait } \\
\text { s }\end{array}$} & \multirow{2}{*}{$\begin{array}{c}\text { Cultivar } \\
\text { s }\end{array}$} & \multirow{2}{*}{ Muta. } & $V p$ & $\mathrm{Vg}$ & P.C. & G.C. & $\mathrm{h}^{2} \%$ & $V p$ & $\mathrm{Vg}$ & P.C. & G.C. & $h^{2} \%$ & GA \\
\hline & & & \multicolumn{5}{|c|}{ M1 } & \multicolumn{6}{|c|}{ M2 } \\
\hline \multirow{7}{*}{ 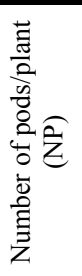 } & \multirow{2}{*}{ NC9 } & S. azide & 165.33 & 132.50 & 0.20 & 0.18 & 80.14 & 174.8 & 139.4 & 0.14 & 0.12 & 79.73 & 21.7 \\
\hline & & G. rays & 102.12 & 66.35 & 0.16 & 0.13 & 64.97 & 663.9 & 581.5 & 0.31 & 0.29 & 87.59 & 46.4 \\
\hline & \multirow{2}{*}{ Gregory } & S. azide & 2100.0 & 1650.0 & 0.56 & 0.50 & 78.57 & 52.16 & 17.56 & 0.07 & 0.04 & 33.67 & 5.01 \\
\hline & & G. rays & $16 \hat{8} .50$ & 150.27 & 0.16 & 0.15 & 89.18 & 289.1 & 263.3 & 0.18 & 0.17 & 91.07 & 31.9 \\
\hline & \multirow{2}{*}{ Bold } & S. azide & 169.00 & 138.67 & 0.51 & 0.46 & 82.05 & 46.29 & 31.01 & 0.22 & 0.18 & 66.99 & 9.39 \\
\hline & & G. rays & 108.00 & 88.50 & 0.41 & 0.37 & 81.94 & 72.53 & 70.49 & 0.29 & 0.29 & 97.19 & 17.0 \\
\hline & \multirow[t]{2}{*}{ Runner } & S. azide & 76.40 & 55.80 & 0.28 & 0.24 & 73.04 & 70.64 & 61.06 & 0.26 & 0.24 & 86.44 & $1 \overline{4} .9$ \\
\hline \multirow{8}{*}{ 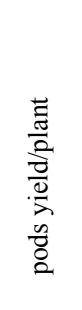 } & & G. rays & 123.08 & 41.28 & 0.33 & 0.19 & 33.54 & 121.4 & 97.50 & 0.34 & 0.30 & 80.31 & $1 \overline{8} .2$ \\
\hline & \multirow{2}{*}{ NC9 } & S. azide & 3.500 & 2.300 & 0.032 & 0.039 & 65.71 & 3.300 & 2.180 & 0.030 & 0.037 & 66.06 & $2 . \hat{4} 7$ \\
\hline & & G. rays & 2.187 & 1.177 & 0.023 & 0.031 & 53.81 & 4.180 & 2.380 & 0.030 & 0.040 & 56.93 & $2 . \overline{39}$ \\
\hline & \multirow{2}{*}{ Gregory } & S. azide & 5.150 & 3.950 & 0.052 & 0.045 & 76.69 & 5.180 & 3.780 & 0.045 & 0.039 & 72.97 & 3.42 \\
\hline & & G. rays & 3.300 & 2.200 & 0.041 & 0.033 & 66.66 & 3.190 & 1.790 & 0.035 & 0.026 & 56.11 & 2.06 \\
\hline & \multirow{2}{*}{ Bold } & S. azide & 4.180 & 2.880 & 0.041 & 0.034 & 68.90 & 4.900 & 3.500 & 0.045 & 0.038 & 71.42 & $3 . \overline{25}$ \\
\hline & & G. rays & 4.500 & 3.380 & 0.042 & 0.037 & 75.11 & 5.100 & 3.870 & 0.045 & 0.039 & 75.88 & $3 . \overline{5} 3$ \\
\hline & \multirow[t]{2}{*}{ Runner } & S. azide & 7.500 & 5.380 & 0.056 & 0.047 & 71.73 & 8.700 & 6.300 & 0.059 & 0.050 & 72.41 & $4 . \hat{4} 0$ \\
\hline \multirow{9}{*}{ 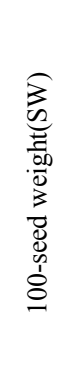 } & & G. rays & 7.400 & 5.290 & 0.055 & 0.047 & 71.48 & 6.800 & 4.640 & 0.051 & 0.043 & 68.23 & 3.66 \\
\hline & \multirow{2}{*}{ NC9 } & S. azide & 68.11 & 65.00 & 0.23 & 0.22 & 95.43 & 67.78 & 63.96 & 0.21 & 0.21 & 94.36 & $1 \overline{6} .0$ \\
\hline & & G. rays & 318.59 & 231.35 & 0.59 & 0.50 & 72.62 & 62.49 & 60.17 & 0.23 & 0.23 & 96.29 & 15.6 \\
\hline & \multirow{2}{*}{ Gregory } & S. azide & 55.44 & 52.83 & 0.23 & 0.23 & 95.29 & 70.40 & 68.14 & 0.25 & 0.24 & 96.79 & 16.7 \\
\hline & & G. rays & 67.25 & 62.89 & 0.25 & 0.24 & 93.52 & 73.43 & 70.42 & 0.24 & 0.24 & 95.90 & $1 \overline{6} .9$ \\
\hline & \multirow{2}{*}{ Bold } & S. azide & 30.33 & 20.73 & 0.17 & 0.14 & 68.35 & 22.11 & 15.01 & 0.14 & 0.11 & 67.89 & 6.58 \\
\hline & & G. rays & 32.47 & 23.10 & 0.17 & 0.14 & 71.14 & 22.66 & 15.29 & 0.13 & 0.11 & 67.48 & 6.62 \\
\hline & \multirow[t]{2}{*}{ Runner } & S. azide & 5.27 & 2.16 & 0.09 & 0.06 & 40.99 & 33.10 & 15.80 & 0.19 & 0.13 & 47.73 & 5.66 \\
\hline & & G. rays & 39.60 & 35.56 & 0.22 & 0.21 & 89.80 & 25.25 & 23.08 & 0.15 & 0.15 & 91.41 & 9.46 \\
\hline
\end{tabular}


These results indicated additive gene action was important for this trait. These results are agreements with Mensah and Obadoni (2007) referred to characters with high heritability can be improved rapidly through selection than those with low heritability, since the latter are influenced by environmental factors in peanut. In respect to expected genetic advance, the High value of expected genetic advance was recorded by Gregory cultivar under both mutagens. While the lowest value (5.94) was obtained from Runner under sodium azide. These results indicated non-additive gene action predominance (dominance or epistasis), which could be exploited through heterosis breeding, also high heritability may not necessary lead to increased genetic gain unless sufficient genetic variability existed in the germplasm. These results were accepted with Abdullah et al. (2007) and Kulkani and Mogle (2013).

\section{III- Phenotypic (r.p) correlation coefficient among} eight characters in $\mathrm{M} 1$ and M2 generations of peanut varieties treated by gamma rays and sodium azide:

The association among some economic characters affected by sodium azide and gamma rays in M1 and M2 generations measured as phenotypic and genotypic correlation coefficients are presented in Tables (15 and 16).

With regard to phenotypic (rp) correlation coefficient, data in Table (15) showed that, the phenotypic correlation for no. of branches/plant was positive with all characters under study in gamma rays in both generations except 100-seed weight in M1 and oil percentage in M2, while this trait gave negative correlation for all traits under sodium azide in both generations except 100-seed weight in M2. Concerning to plant height, the phenotypic correlation under sodium azide and the gamma rays appears positive correlations for all traits under study except seed yield $(-0.388)$ in gamma rays and oil \% (-0.051) under sodium azide in M2 generation. For no. of pods/plant, under the effect of sodium azide the results appear the rp have moderate and high positive correlations with each of pod yield/plant (0.684 and 0.580) and seed yield/plant $(0.685$ and 0.502$)$ in both generation, respectively. On the other side under gamma ray, no. of pods/plant gave high and positive rp for all characters except oil \% in M1 generation and weak positive under M2 generations. Pod yield/plant under the effect of sodium azide appears high positive correlation coefficients with seed yield/plant (0.869 and 0.928) during two generations and 100 -seed weight $(0.643)$ in M1 generation. While it was weakly positive correlated with oil content $(0.164$ and 0.443$)$ in both generations. However, it was negatively correlated with 100 -seed weight $(-0.078)$ in M2 generation. Further pod yield/plant under the effect of gamma rays was found to be highly positive correlated with seed yield/plant (0.924 and 0.505) and 100-seed weight (0.579 and 0.746 ) in both generations. However, it was weakly positive correlated with oil content $(0.003$ and 0.022$)$ in M1 and M2 generation, respectively. Seed yield/plant gave the high and positive correlation with 100 -seed weight $(0.655$ and 0.648$)$ under both mutagens in M1, However, it was weakly positive correlated with oil content in M1 and M2 generation.

Table (15): Phenotypic (r.p) correlation coefficient among eight characters in M1 and M2 generations of peanut varieties treated by gamma rays and sodium azide

\begin{tabular}{|c|c|c|c|c|c|c|c|c|}
\hline Traits & Gene. & Muta. & $\begin{array}{c}\text { Plant } \\
\text { height }\end{array}$ & $\begin{array}{c}\text { No. of pods/ } \\
\text { plant }\end{array}$ & $\begin{array}{c}\text { Pod yield/ } \\
\text { plant }\end{array}$ & Seed yield & $\begin{array}{c}100 \text {-seed } \\
\text { weight }\end{array}$ & Oil \% \\
\hline $\begin{array}{l}\text { No. of } \\
\text { branches/plant }\end{array}$ & M1 & S. Azd. & $-0.85^{*}$ & -0.426 & -0.482 & -0.378 & $-0.681^{*}$ & -0.267 \\
\hline & M2 & $\begin{array}{c}\text { Gam. } \\
\text { S. Azd. } \\
\text { Gam. }\end{array}$ & $\begin{array}{c}0.341 \\
-0.275 \\
0.210\end{array}$ & $\begin{array}{c}0.367 \\
-0.463 \\
0.055\end{array}$ & $\begin{array}{c}0.304 \\
-0.353 \\
0.387\end{array}$ & $\begin{array}{c}0.337 \\
-0.483 \\
0.208\end{array}$ & $\begin{array}{c}-0.061 \\
0.129 \\
0.231\end{array}$ & $\begin{array}{l}0.282 \\
-0.356 \\
-0.013\end{array}$ \\
\hline plant height & $\begin{array}{l}\text { M1 } \\
\text { M2 }\end{array}$ & $\begin{array}{c}\text { S. Azd. } \\
\text { Gam. } \\
\text { S. Azd. } \\
\text { Gam. }\end{array}$ & & $\begin{array}{c}0.41 \\
0.722^{*} \\
0.473 \\
0.392\end{array}$ & $\begin{array}{c}0.529^{*} \\
0.24 \\
0.531 * \\
0.435\end{array}$ & $\begin{array}{c}0.345 \\
0.639^{*} \\
0.510^{*} \\
-0.388\end{array}$ & $\begin{array}{c}0.528 * \\
0.436 \\
0.453 \\
0.293\end{array}$ & $\begin{array}{c}0.226 \\
0.024 \\
-0.051 \\
0.833 *\end{array}$ \\
\hline $\begin{array}{l}\text { No. of } \\
\text { pods/plant }\end{array}$ & M1 & S. Azd. & & & $0.684 *$ & $0.685^{*}$ & 0.484 & 0.146 \\
\hline & M2 & $\begin{array}{c}\text { Gam. } \\
\text { S. Azd. } \\
\text { Gam. }\end{array}$ & & & $\begin{array}{c}0.929^{*} \\
0.58^{*} \\
0.409^{*}\end{array}$ & $\begin{array}{c}0.927^{*} \\
0.502 * \\
0.252\end{array}$ & $\begin{array}{c}0.541^{*} \\
-0.275 \\
0.345\end{array}$ & $\begin{array}{c}0.018 \\
0.458 \\
0.19\end{array}$ \\
\hline Pod yield/plant & M1 & $\begin{array}{l}\text { S. Azd. } \\
\text { Gam. }\end{array}$ & & & & $\begin{array}{l}0.869^{*} \\
0.924 *\end{array}$ & $\begin{array}{l}0.643 * \\
0.579 *\end{array}$ & $\begin{array}{l}0.164 \\
0.003\end{array}$ \\
\hline & M2 & $\begin{array}{l}\text { S. Azd. } \\
\text { Gam. }\end{array}$ & & & & $\begin{array}{l}0.928^{*} \\
0.505^{*}\end{array}$ & $\begin{array}{l}-0.078 \\
0.746^{*}\end{array}$ & $\begin{array}{l}0.443 \\
0.022\end{array}$ \\
\hline Seed yield/plant & M1 & $\begin{array}{l}\text { S. Azd. } \\
\text { Gam. }\end{array}$ & & & & & $\begin{array}{l}0.655^{*} \\
0.648^{*}\end{array}$ & $\begin{array}{l}0.269 \\
0.042\end{array}$ \\
\hline & M2 & $\begin{array}{l}\text { S. Azd. } \\
\text { Gam. }\end{array}$ & & & & & $\begin{array}{l}-0.122 \\
0.469\end{array}$ & $\begin{array}{c}0.352 \\
-0.057\end{array}$ \\
\hline 100-seed weight & $\begin{array}{l}\text { M1 } \\
\text { M2 }\end{array}$ & $\begin{array}{c}\text { S. Azd. } \\
\text { Gam. } \\
\text { S. Azd. } \\
\text { Gam. }\end{array}$ & & & & & & $\begin{array}{c}0.372 \\
-0.486 \\
0.126 \\
-0.212\end{array}$ \\
\hline
\end{tabular}


Regarding to genotypic (r.g) correlation coefficient, data in Table (16) showed that no. of branches/plant gave a high and negative correlation with all traits under study in sodium azide in both generation except 100-seed weight in M2 (0.176). While for the number of branches/plant appeared positive correlation with all traits under gamma rays in both M1 and M2 except 100 -seed weight $(-0.230)$ in M1 and oil percentage (-0.699) in M2. Plant height, genotypic correlation appears a high and positive correlation for all traits except pod yield (-0.822) under gamma rays in M1 and 100-seed weight $(-0.364)$ and seed yield (-0.699) in gamma rays and oil \% (-0.334) under sodium azide in M2 generation. For number of pods/plant, under the effect of sodium azide the results appear that the rg have high positive correlation with pod/yield/plant (0.801 and 0.709) and seed yield/plant $(0.726$ and 0.808$)$ in both generations, respectively. On the other side, no. of pods/plant gave high and positive rg for all characters in M1 and M2 except oil \% in M1 and M2, also, with seed yield/plant in M2 under gamma ray.

Regarding to pod yield/plant under the effect of sodium azide appears a high and moderate positive correlation coefficients with seed yield/plant $(0.748$ and 0.645$)$ and 100 -seed yield (0.798 and 0.442$)$ in two generations respectively, while pod yield/plant was weakly correlated with oil content in both generations. Further pod yield/plant was found to be highly positive correlated in most cases with seed yield/plant $(0.912$ and 0.277$)$ and 100 -seed weight $(0.654$ and 0.850$)$ in both generations under the effect of gamma rays. However, it was weakly positive correlated with oil content (-0.076 and -0.290$)$ in M1 and M2 generation, respectively. Seed yield/plant gave high and positive correlation with 100 -seed weight $(0.931$ and 0.834$)$ under both mutagens in M1 and (0.771) under gamma rays in M2; however, it was positive correlated with oil content in M1 and M2 generations under sodium azide and negative correlation under gamma rays. The trait of 100-seed weight gave a weak and negative genotypic correlation in most cases with oil percentage.

Finally, in general the genotypic correlation coefficients were mostly higher than the phenotypic correlation coefficients indicating strong inherent association among the studied characters. Many researchers obtained similar results (Babariya and Dobariya, 2012; Ashutosh et al., 2016; Thirumala Rao, 2016; Rajarathinam et al., 2017; Reddy et al., 2017; Shankar et al., 2018).

Table (16): Genotypic (r.g) correlation coefficient among eight characters in M1 and M2 generations of peanut varieties treated by gamma rays and sodium azide

\begin{tabular}{|c|c|c|c|c|c|c|c|c|}
\hline Traits & Gene. & Muta. & $\begin{array}{l}\text { Plant } \\
\text { height }\end{array}$ & $\begin{array}{l}\text { No. of } \\
\text { pods/ } \\
\text { plant }\end{array}$ & $\begin{array}{l}\text { Pod yield/ } \\
\text { plant }\end{array}$ & Seed yield & $\begin{array}{c}\text { 100-seed } \\
\text { weight }\end{array}$ & Oil \% \\
\hline \multirow{4}{*}{$\begin{array}{l}\text { No. of } \\
\text { branches/plant }\end{array}$} & \multirow[t]{2}{*}{ M1 } & S. Azd. & $-0.799 *$ & $-0.666^{*}$ & $-0.830^{*}$ & $-0.804 *$ & $-0.888^{*}$ & $-0.442 *$ \\
\hline & & Gam. & $0.878^{*}$ & $0.777 *$ & $0.790^{*}$ & $0.608^{*}$ & -0.230 & $0.747 *$ \\
\hline & \multirow[t]{2}{*}{ M2 } & S. Azd. & $-0.810^{*}$ & $-0.760^{*}$ & $-0.852 *$ & $-0.777 *$ & 0.176 & $-0.804^{*}$ \\
\hline & & Gam. & 0.280 & $0.585^{*}$ & $0.726^{*}$ & 0.235 & 0.402 & $-0.699 *$ \\
\hline \multirow[t]{4}{*}{ plant height } & \multirow[t]{2}{*}{ M1 } & S. Azd. & & $0.541 *$ & $0.597 *$ & $0.564 *$ & $0.677^{*}$ & 0.304 \\
\hline & & Gam. & & $0.784^{*}$ & $-0.822 *$ & $0.834 *$ & $0.628^{*}$ & 0.281 \\
\hline & \multirow[t]{2}{*}{ M2 } & S. Azd. & & $0.699^{*}$ & $0.764 *$ & $0.703^{*}$ & 0.427 & -0.334 \\
\hline & & Gam. & & $0.788^{*}$ & 0.337 & $-0.699 *$ & -0.364 & $0.570 *$ \\
\hline \multirow{4}{*}{$\begin{array}{l}\text { No. of } \\
\text { pods/plant }\end{array}$} & \multirow[t]{2}{*}{ M1 } & S. Azd. & & & $0.801 *$ & $0.762 *$ & $0.992 *$ & $-0.514^{*}$ \\
\hline & & Gam. & & & $0.877 *$ & $0.864 *$ & $0.671^{*}$ & -0.169 \\
\hline & \multirow[t]{2}{*}{ M2 } & S. Azd. & & & $0.709 *$ & $0.808^{*}$ & $-0.605 *$ & $0.665^{*}$ \\
\hline & & Gam. & & & $0.941 *$ & -0.149 & $0.461^{*}$ & -0.075 \\
\hline \multirow[t]{4}{*}{ Pod yield/plant } & \multirow[t]{2}{*}{ M1 } & S. Azd. & & & & $0.748^{*}$ & $0.798^{*}$ & 0.168 \\
\hline & & Gam. & & & & $0.912 *$ & $0.654 *$ & -0.076 \\
\hline & \multirow[t]{2}{*}{ M2 } & S. Azd. & & & & $0.645^{*}$ & $0.442 *$ & 0.170 \\
\hline & & Gam. & & & & 0.277 & $0.850^{*}$ & -0.290 \\
\hline \multirow{4}{*}{$\begin{array}{l}\text { Seed } \\
\text { yield/plant }\end{array}$} & \multirow[t]{2}{*}{ M1 } & S. Azd. & & & & & $0.931 *$ & 0.194 \\
\hline & & Gam. & & & & & $0.834^{*}$ & -0.207 \\
\hline & \multirow[t]{2}{*}{ M2 } & S. Azd. & & & & & $-0.772 *$ & $0.548^{*}$ \\
\hline & & Gam. & & & & & 0.771 & $-0.773^{*}$ \\
\hline \multirow[t]{4}{*}{$\begin{array}{l}\text { 100-seed } \\
\text { weight }\end{array}$} & \multirow[t]{2}{*}{ M1 } & S. Azd. & & & & & & 0.464 \\
\hline & & Gam. & & & & & & $-0.917^{*}$ \\
\hline & \multirow[t]{2}{*}{ M2 } & S. Azd. & & & & & & $0.421 *$ \\
\hline & & Gam. & & & & & & $-0.833^{*}$ \\
\hline
\end{tabular}




\section{REFERENCES}

Abdullah, T., A. A. Rahmianna, S. Hardaningsih and F. Rozi (2007). Increasing peanut yield on dry land Alfisols in Indonesia. Journal of SAT Agricultural Research, 5(1): 45-47.

Abdul Rahaman, A. A., A. A. Afolabi, B. U. Olayinka, O. T. Mustapha, K. A. Abdulkareem and F. A. Oladele (2013). Effects of sodium azide and nitrous acid on the morphology and leaf Anatomy of Jatropha curcas L. (Euphorbiaceae). International Journal of Phytofuel and Allied Sciences, 2: 30-41.

Allard, R. W. (1964). Principles of Plant Breeding. John Willey and Sons, New York. Pp. 20-24 and 88-89.

Animasaun, D. A., S. Oyedeji, M. A. Azeez and O. AO (2014). Alkylating efficiency of sodium azide on pod yield, nut size and nutrition composition of samnut 10 and samnut 20 varieties of peanut (Arachis hypogea L.). African Journal of Food, Agriculture, Nutrition and Development, 14(7):9497-9510.

Aparna, M., C. Anurag, M. Sreedhar, K. D. Pavan, P. Venu-Babu and R. K. Singhal (2012). Impact of gamma rays on the seed germination and seedling parameters of peanut (Arachis hypogaea L.). Asian Journal of Experimental Biological sciences, 4(1): 113-118.

Ashutosh, K., G. Soma, R. S. Sheetal and K. Pradhan (2016). Genetic variability, correlation coefficient and path coefficient analysis for yield and component traits in peanut. Indian $\mathrm{J}$. Eco., 43(2): 85-89.

Babariya, C. A. and K. L. Dobariya ( 2012). Correlation coefficient and path coefficient analysis for yield components in peanut (Arachis hypogaea L.). Electronic J. Plant Breed., 3(3): 932-938.

Badigannavar, A. M. and G. S. Murty (2007). Genetic enhancement of peanut through gamma ray induced mutagenesis. Plant Mutation Reports, 1(3): 16-21.

Bolbhat, S. N and K. N. Dhumal (2012). Effect of mutagens on quantitative characters in M2 and M3 generation of hoersegram (Macrotyloma uniflorum (Lam.) Verdc). International Journal of Scientific and Research Publication, 2(10): 1-7.

Channayya, P. H., H. L. Nadaf and C. M. Keerthi (2011). Induced genetic variability and correlation studies for yield and its component traits in Peanut (Arachis hypogaea L.) Electronic Journal of Plant Breeding, 2(1): 135-142.

Cheong-Youngkoun, Doo-Hong, Park-Kittun, ChoSangkyun, Ko-Jong Chul, RyuJeomho and KimSoopong (2004). Growth characteristics in progenies of peanut mutants induced by gammaray. Korean Journal of Breeding, 36(5): 266-270.

Dubey, A. K., J. R. Yadav and B. Singh (2007). Studies on induced mutations by gamma ray. Madras Agricultural Journal, 56(5): 239-243.

FAOSTAT (2020). Food and Agriculture Organization of the United Nations. Available online: http://wwwfaoorg/ accessed on Jan 30 (2020).

Gemechis, W. (2018). In-Vitro Induction of Mutation in Peanut (Arachis hypogea L.) by Using
Sodium Azide Mutagens and Its Impact on Selected Agronomic Traits". Annals of Ecology and Environmental Science, 2(3): 27-32.

Gunasekaran, A. and P. Pavadai (2015). Studies on induced physical and chemical mutagenesis in peanut (Arachis hypogia L.). International Letters of Natural Sciences, 8: 25-3.

Habtamu, A. (2016). Review Paper on Mutation Breeding as Applied in Peanut (Arachis hypogea L.) Improvement. Gene and Cell Therapy, 1(5): 35-40. doi: 10.11648/j.gct.20160105.11.

Isleib, T. G., J. C. Wynne and S. N. Nigam (1994). Peanut breeding, in The Peanut Crop: A Scientific Basis for Improvement, ed. Smartt J. (London: Chapman \& Hall), 552-623.

Jadhav, V. M., K. Z. Rahul and D. S. Amol (2018). Studies on induced chemical mutagenesis in peanut (Arachis hypogaea L.). Int. J. Curr. Microbiol. App. Sci., 7(10): 1662-1669.

Janila, P., S. N. Nigam, M. K. Pandey, P. Nagesh and R. K. Varshney (2013). Peanut improvement: use of genetic and genomic tools. Frontiers in Plant Science, 4: 1-16.

Jaywardena, S. D. L. and R. Peiris (1988). Food crop breeding in Srilanks-Archivements and challenges. Biol. News, 2: 22-34.

Kamble, G. C. and A. S. Patil (2014). Comparative mutagenicity of EMS and gamma radiation in wild chickpea. International Journal of Science, Environment, 3(1): 166-180.

Kashid, N. G. and S. B. More (2016). A study of effect of induced mutation on flowering of plant in M2 \& M3 generations in chickpea (Cicer arietinum L.). Tropical Plant Research, 3(1): 182-185.

Kavera, H. and H. L. Nadaf (2017). Genetic improvement for yield through induced mutagenesis in peanut (Arachis hypogaea L.). Legume Research, 40(1): 32-35.

Kulkani, G. B. and U. P. Mogle (2013). Effects of mutagen on chlorophyll mutation in horse gram [Macrotylo mauniflorum (Lam) Verdcourt]. Bioscience Discovery, 4(2): 214-219.

Kulkani, G. B. and U. P. Mogle (2013). Effects of mutagen on chlorophyll mutation in horse gram [Macrotyloma uniflorum (Lam) Verdcourt]. Bioscience Discovery, 4(2): 214-219.

Kyaw, H., K. Winn, T. Lin and N. Mar Htwe (2017). correlation and path coefficient analysis in peanut (Arachis hypogaea L.) under monsoon and post monsoon. Int. J. Adv. Res. 5(12): 175-183.

Lagoda, P. J. L. (2009). Networking and Forecasting of Cooperation I Plant Mutation Genetics and Breeding: Role of the Joint FAO/IAEA Division. Q.Y. Shu (ed.). Induced Plant Mutation in the Genomic Era, Food and Agriculture organization of the United Nations, Rome, 27-30.

Lopez. Y., D. D. Smith, S. A. Senseman and W. L. Rooney (2001). Genetic factors influencing high oleic acid content in Spanish market- type peanut cultivars. Crop Sci., 41: 51-56.

Mensah, J. K. and B. Obadoni (2007). Effects of sodium azide on yield parameters of peanut (Arachis hypogaea L.). African Journal of Biotechnology, 6(6): 668-671. 
Miller, P. J., J. C. Willianis, H. F. Robinson and R. F. Comostock (1958). Estimates of genotypic and environmental variance and covariance in upland cotton and their implication in selection. Agron. J., 50: 126-131.

Mishra, D., B. Singh and R. Sahu (2013). Gamma Ray Induced Macro-Mutations in Green gram [Vigna radiata(L.) Wilczek]. International Journal of Agriculture and Forestry, 3: 105-109.

Muniappan, V., S. Palanivel and S. Parvathi (2016). Impact of Ethyl Methane Sulphonate on M1 Attributes of Peanut with Special Emphasis of Amino Acid Profiling. JOAASR-RTB-2016February-2016: 100-108.

Padmaja, D., K. B. Eswari, M. V. Brahmeswara Rao and G. Prasad (2015). Genetic variability studies in F2 population of Peanut (Arachis hypogeaea L.). Helix, 2: 668-672.

Rajarathinam, P., M. Narayana, M. Alagirisamy and I. S. Moshin (2017). Variability, correlation and path coefficient analysis in peanut (Arachis hypogaea L.). S. Vignesh and A. Philip Arokiadoss (ed.) Statistical Approaches on Multidisciplinary Research, Volume I, Surragh Publishers,

India.

DOI://doi.org/10.5281/zenodo.262967.

Reddy, A. T., M. ReddiSekhar, A. Vijayabharathi, T. Lakshmi, G. Pathy, R. Lakshmikantha and V. Jayalakshmi (2017). Correlation And Path Analysis Of Kernel Yield And Its Components In Peanut (Arachis hypogaea L.). Int. J. Curr. Microbiol. App. Sci., 6(12): 10-16.

Roychowdhury, R., S. Datta, P. Gupta and J. Tah (2012). Analysis of genetic parameters on mutant populations of Mungbean (Vigna radiata L.) after ethyl methane sulphonate treatment. Not. Sci. Biol., 4: 137-143.
Schum, A. (2003). Mutation breeding in ornamentals and efficient breeding method. Acta Hort, 612: 47-60.

Shankar, M., B. N. Harish Babu, R. Gobu and Sheshaiah (2018). A Study of Correlation and Path Analysis in Peanut (Arachis hypogaea L.) Bull. Env. Pharmacol. Life Sci., 7[12]: 111-114.

Siddiqui, S., M. K. Meghvansi and H. Zia-ul (2007). Cytogenetic changes induced by Sodium Azide (NaN3) on Trigonella foenum- graecum seeds. South African Journal of Botany, 73: 632-635.

Singh, R. K. and B. D. Chaudhary (1985). Biometric Methods in Quantitative Genetic Analysis. Kalyani Publishers, New Delhi. India.

Steel, R. G. D., J. H. Torrie and D. A. Dickey (1997). Principles and Procedures of Statistics: A Biometrical Approach ( $3^{\text {rd }}$ ed.). McGraw- Hill, New York.

Thirumala Rao, V. (2016). Genetic variability, correlation and path coefficient analysis under drought in peanut (Arachis hypogaea L.). Legume Res., 39(1): 319-322.

Tingting, C., H. Luping, W. Miaomiao, H. Yang, Z. Ruier, W. Xinyue, W. Leidi, W. Shubo and Z. Lei (2020). Ethyl Methyl Sulfonate-Induced Mutagenesis and Its Effects on Peanut Agronomic, Yield and Quality Traits. Agronomy, 10: 655.

Tingting, C., H. Luping, W. Miaomiao, H. Yang, Z. Ruier, W. Xinyue, W. Leidi, W. Shubo and Z. Lei (2020). Ethyl Methyl Sulfonate-Induced Mutagenesis and Its Effects on Peanut Agronomic, Yield and Quality Traits.Agronomy, 10: 655.

Wani, M. R. and S. Khan (2006). Estimates of genetic variability in mutated populations and the scope of selection for yield attributes in Vigna radiata (L.) Wilczek. Egypt. J. Biol., 8: 1-6.

\section{التحسين الور اثي للمحصول ومكوناته من خلال إحداث المطفرات الكيميائية والفيزيائية في الفول السوداني

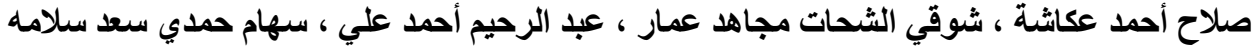

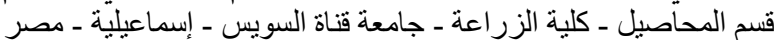

أجريت هذه الدر اسة بمزر عة خاصة بمحافظة الثرقية تحت إثر اف كلية الزر اعة ـ جامعة قناة السويس، الإسماعيلية، مصر . تم استخدام أربعة

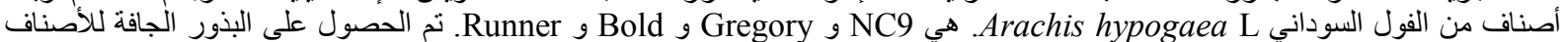

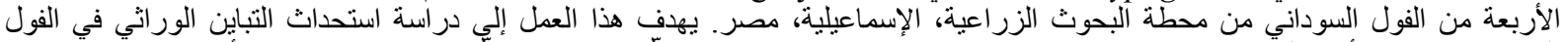

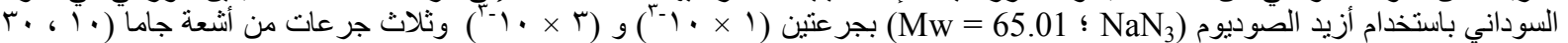

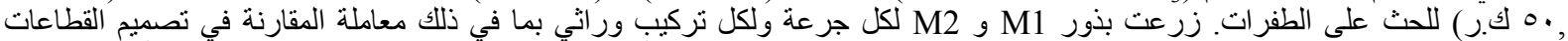

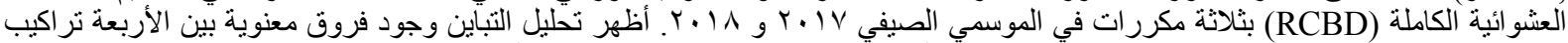

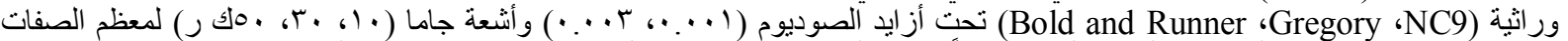

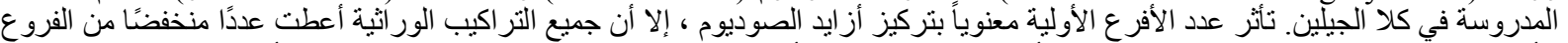

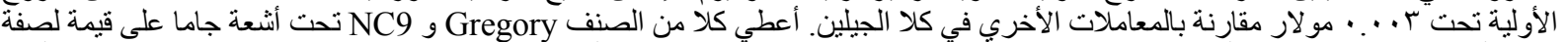

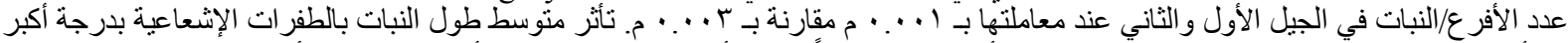

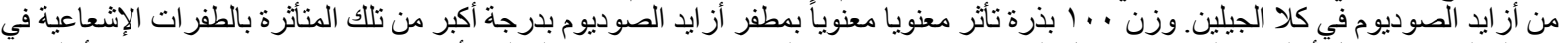

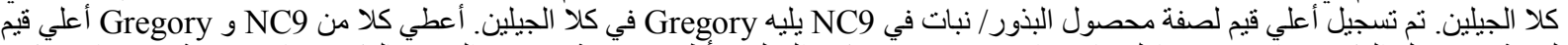

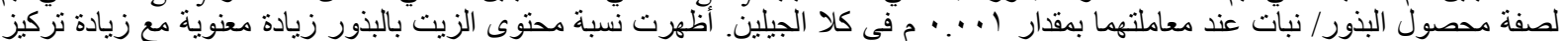

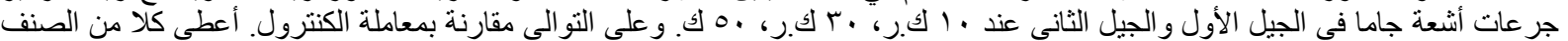

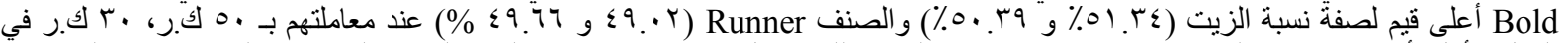

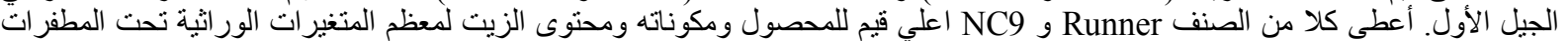

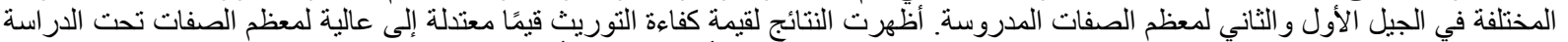

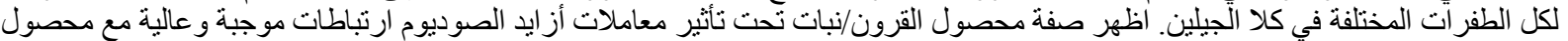

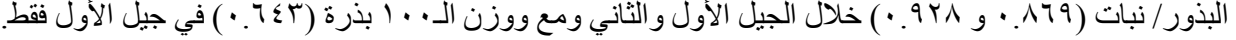

